\title{
Structural characterization and magnetic properties of chromium jarosite $\mathrm{KCr} 3(\mathrm{OD}) 6(\mathrm{SO} 4) 2$
}

Janas, Sofie; Sørensen, Mathilde B; Andersen, Anders B A; Juelsholt, Mikkel; Boehm, Martin; Pedersen, Kasper Steen; Jensen, Kirsten M Ø; Lefmann, Kim; Nielsen, Ulla Gro

Published in:

Physical Chemistry Chemical Physics

Link to article, DOI:

10.1039/d0cp04978f

Publication date:

2020

Document Version

Peer reviewed version

Link back to DTU Orbit

Citation (APA):

Janas, S., Sørensen, M. B., Andersen, A. B. A., Juelsholt, M., Boehm, M., Pedersen, K. S., Jensen, K. M. Ø., Lefmann, K., \& Nielsen, U. G. (2020). Structural characterization and magnetic properties of chromium jarosite $\mathrm{KCr}_{3}(\mathrm{OD})_{6}\left(\mathrm{SO}_{4}\right)_{2}$. Physical Chemistry Chemical Physics, 22, 25001-25010. https://doi.org/10.1039/d0cp04978f

\section{General rights}

Copyright and moral rights for the publications made accessible in the public portal are retained by the authors and/or other copyright owners and it is a condition of accessing publications that users recognise and abide by the legal requirements associated with these rights.

- Users may download and print one copy of any publication from the public portal for the purpose of private study or research.

- You may not further distribute the material or use it for any profit-making activity or commercial gain

- You may freely distribute the URL identifying the publication in the public portal 


\title{
Structural characterization and magnetic properties of chromium jarosite $\mathrm{KCr}_{3}(\mathrm{OD})_{6}\left(\mathrm{SO}_{4}\right)_{2}^{\dagger}$
}

\author{
Sofie Janas ${ }^{a b}$, Mathilde B. Sørensen ${ }^{a}$, Anders B. A. Andersen ${ }^{c}$, Mikkel Juelsholt ${ }^{f}$, Martin Boehm ${ }^{d}$, Kasper S. Pedersen ${ }^{e}$ \\ Kirsten M. Ø. Jensen ${ }^{f}$, Kim Lefmann $^{a}$, Ulla Gro Nielsen ${ }^{c *}$
}

Potassium chromium jarosite, $\mathrm{KCr}_{3}(\mathrm{OH})_{6}\left(\mathrm{SO}_{4}\right)_{2}(\mathrm{Cr}$-jarosite), is considered a promising candidate to display spin liquid behavior due to the strong magnetic frustration imposed by the crystal structure. However, the ground state magnetic properties have been debated, since Cr-jarosite is notoriously non-stoichiometric. Our study reports the magnetic properties for deuterated $\mathrm{KCr}_{3}(\mathrm{OD})_{6}\left(\mathrm{SO} \mathrm{O}_{4}\right)_{2}$ on chemically well-defined samples, which have been obtained by a combination of powder X-ray diffraction, neutron diffraction, solid state NMR spectroscopy, and scanning electron microscopy with energy dispersive spectroscopy. Eight polycrystalline samples, which all only contained $1-3 \% \mathrm{Cr}$ vacancies were obtained. However, significant substitution (2-27\%) of potassium with $\mathrm{H}_{2} \mathrm{O}$ and/or $\mathrm{H}_{3} \mathrm{O}^{+}$was observed and resulted in pronounced stacking disorder along the $c$-axis. A clear second-order transition to an antiferromagnetically ordered phase at $T_{\mathrm{N}}=3.8(1) \mathrm{K}$ with a small net moment, $0.03 \mu_{\mathrm{B}}$, per $\mathrm{Cr}^{3+}$-ion was obtained from vibrating sample magnetometry and temperature dependent neutron diffraction. The moment is attributed to spin canting caused by the Dzyaloshinskii-Moriya interaction. Thus, our experimental results imply that even ideal potassium chromium jarosite will exhibit magnetic order below $4 \mathrm{~K}$ and therefore it does not qualify as a true spin liquid material.

\section{Introduction}

Frustrated magnetism, which is the suppression of magnetic ordering of spins, may be induced by the geometrical location of magnetic ions on certain crystal lattices in combination with antiferromagnetic coupling to neighboring spins. This leads to fascinating and intensely studied magnetic properties including exotic low-temperature phases such as spin ice and the elusive quantum spin liquids, where the magnetic order is suppressed altogether. $1+3$

Antiferromagnets with a two-dimensional kagomé lattice are some of the most promising systems to display quantum spin liquid behavior and have received much theoretical attention. 4.7 However, indisputable experimental evidence of a quantum spin liquid phase has yet to be found. $\frac{8}{6}$ For example, herbertsmithite, $\mathrm{ZnCu}_{3}(\mathrm{OH})_{6} \mathrm{Cl}_{2}$, has been extensively studied, but the intrinsic structural disorder (mixed $\mathrm{Zn}(\mathrm{II})(S=0)$ and $\mathrm{Cu}(\mathrm{II})(S=1 / 2)$ occupancy) disrupts the magnetic lattice. ${ }^{9}$ Very recently, a novel Ti(III) kagomé compound, $\left(\mathrm{CH}_{3} \mathrm{NH}_{3}\right)_{2} \mathrm{NaTi}_{3} \mathrm{~F}_{12}$, was reported, which shows no long-range magnetic order down to $0.1 \mathrm{~K} .10$ However, the interlayer $\mathrm{CH}_{3} \mathrm{NH}_{3}{ }^{+}$-ions are statistically disordered, which disrupts the local magnetic environment. ${ }^{[10}$ This demonstrates the general challenge of obtaining structurally non-disordered kagomé lattice systems.

Jarosites are a popular class of magnetic compounds, where

\footnotetext{
0 a Niels Bohr Institute, University of Copenhagen, DK-2100 Copenhagen $\emptyset$, Denmark

${ }^{0 b}$ Laboratory for Quantum Magnetism, Institute of Physics, EPFL, 1015 Lausanne, Switzerland.

${ }^{0 c}$ Department of Physics, Chemistry, and Pharmacy, University of Southern Denmark, Campusvej 55, 5230 Odense M, Denmark.E-mail: ugn@sdu.dk

0d Institut Max von Laue Paul Langevin, 38042 Grenoble, France.

oe Department of Chemistry, Technical University of Denmark, DK-2800 Kgs. Lyngby, Denmark.

${ }^{0 f}$ Department of Chemistry and Nano-Science Center, University of Copenhagen, DK2100 Copenhagen $\emptyset$, Denmark.

${ }^{0} \uparrow$ Electronic Supplementary Information (ESI) available containing: detailed synthesis details, Rietveld refinement of x-ray diffraction data and ${ }^{2} \mathrm{H}$ MAS-NMR data for all samples; scanning electron microscopy pictures, Rietveld refinement of neutron diffraction data, and details regarding temperature dependent neutron diffraction for selected samples. See DOI: 10.1039/cXCP00000x/
}

the ideal crystal structure contains perfect, stacked kagomé lattices. However, studies of these compounds have so far also been plagued by structural disorder. Jarosites are an isostructural group of minerals and materials (space group $R \overline{3} \mathrm{~m})^{11}$ with the chemical formula $\mathrm{AM}_{3}(\mathrm{OH})_{6}\left(\mathrm{SO}_{4}\right)_{2}$ where $\mathrm{A}$ is a monovalent ion $\left(\mathrm{K}^{+}\right.$, $\mathrm{Na}^{+}, \mathrm{Rb}^{+}, \mathrm{NH}_{4}^{+}, \mathrm{H}_{3} \mathrm{O}^{+}, \mathrm{Rb}^{+}, \mathrm{Ag}^{+}$) and $\mathrm{M}$ is a trivalent metal ion $\left(\mathrm{V}^{3+}, \mathrm{Cr}^{3+}, \mathrm{Fe}^{3+}\right) .712$ The magnetic properties of iron (III) jarosite, $\mathrm{KFe}_{3}(\mathrm{OH})_{6}\left(\mathrm{SO}_{4}\right)_{2}$, have been widely studied as the Fespins $(S=5 / 2)$ exhibit strong classical frustration.7|13]14 In contrast, vanadium jarosites $\left(\mathrm{M}=\mathrm{V}^{3+}, S=1\right)$ are non-frustrated ferromagnets. 15,16

The magnetic properties of the third member, chromium(III) jarosites $\left(\mathrm{M}=\mathrm{Cr}^{3+}, S=3 / 2\right.$, mainly $\left.\mathrm{KCr}_{3}(\mathrm{OH})_{6}\left(\mathrm{SO}_{4}\right)_{2}\right)$ have been investigated, but contradicting results reported.7]12]17.24 The smaller spin value for $\mathrm{Cr}$ as compared to Fe combined with the low number of nearest neighbors $(z=4)$ and strong geometric frustration may potentially lead to observable quantum effects. This may place Cr-jarosite in the fascinating zone between the strictly quantum $(S=1 / 2)$ spin liquids and frustrated systems with classical spin values.

The ideal crystal structure of jarosite (Fig. 1) contains a 2D kagomé lattice where stacked planes of corner sharing triangles are arranged such that six-triangle rings are formed in the planes. 27 It is this corner-sharing geometry that favors a non-collinear magnetic structure, typical for 2D frustrated systems, in turn leading to a large degeneracy and low-temperature correlated disorder, characteristic of a spin liquid. The magnetic ions are coordinated to four equatorial $\mathrm{OH}$ groups, that each is bonded to two neighboring magnetic ions, and two axial bonds to the sulfate group. The octahedra are tilted towards the center of the magnetic subunit and capped by tetrahedral sulfate groups that are positioned alternately above and below the octahedral sheets (Fig. 1a). 7 The A-ions are positioned between the layers and there is a direct correlation between the interlayer spacing and the size of the A-ion. 12 
Table 1: Synthesis details, stoichiometry, and magnetic properties of Cr-jarosites given in literature compared to our study. N/A refers to values either not measured or not stated.

\begin{tabular}{|c|c|c|c|c|c|c|c|}
\hline $\begin{array}{l}\text { Synthesis } \\
\text { Method }\end{array}$ & $\begin{array}{l}\text { Temperature } \\
\left({ }^{\circ} \mathrm{C}\right)\end{array}$ & $\begin{array}{l}\text { Duration } \\
\text { (hours) }\end{array}$ & $\begin{array}{l}\text { Cr occupancy } \\
(\%)\end{array}$ & $\begin{array}{l}T_{N} \\
(\mathrm{~K})\end{array}$ & $\begin{array}{l}\theta_{C W} \\
(\mathrm{~K})\end{array}$ & Magnetic ordering & $\begin{array}{l}\text { Reference } \\
\text { (First author, year) }\end{array}$ \\
\hline $\operatorname{Reflux}^{a}$ & $\mathrm{~N} / \mathrm{A}$ & $\mathrm{N} / \mathrm{A}$ & $\mathrm{N} / \mathrm{A}$ & $1-2$ & -67.5 & Antiferromagnetic ordering & Townsend, $1986^{25}$ \\
\hline Hydrothermal $^{b}$ & 210 & 16 & $81(3)$ & $\mathrm{N} / \mathrm{A},<2$ & $-78(10)$ & Spin glass & Wills, 199624 \\
\hline Reflux $^{a}$ & N/A & $\mathrm{N} / \mathrm{A}$ & $\mathrm{N} / \mathrm{A}$ & 2 & $\mathrm{~N} / \mathrm{A}$ & Spin-glass, fluctuations $>25 \mathrm{mK}$ & Keren, 199618 \\
\hline $\operatorname{Reflux}^{a}, \mathrm{~A}$ & N/A & N/A & 100 & 1.8 & $-70(5)$ & Antiferromagnetic ordering & Lee, 199717 \\
\hline Reflux $^{a}, \mathrm{~B}$ & $\mathrm{~N} / \mathrm{A}$ & $\mathrm{N} / \mathrm{A}$ & $76(5)$ & 1.55 & $-54(2)$ & $120^{\circ}$ magnetic ordering, $q=0$ & Lee, 199717 \\
\hline Hydrothermal & 280 & 55 & $95(3)$ & 4.0 & $\mathrm{~N} / \mathrm{A}$ & Fluctuating $120^{\circ}$ magnetic ordering & Inami, $2001^{19}$ \\
\hline $\mathrm{N} / \mathrm{A}$ & $\mathrm{N} / \mathrm{A}$ & N/A & N/A & 4.2 & $\mathrm{~N} / \mathrm{A}$ & $120^{\circ}$ magnetic ordering, $q=0$ & Nishiyama, $2001^{20}$ \\
\hline Hydrothermal $^{b}$, I & 280 & 50 & $\mathrm{~N} / \mathrm{A}$ & 4.1 & -49 & $120^{\circ}$ magnetic ordering, $q=0$ & Morimoto, $2003^{21}$ \\
\hline Hydrothermal $^{c}$, II & 280 & 50 & $\mathrm{~N} / \mathrm{A}$ & 3.9 & -52 & $120^{\circ}$ magnetic ordering, $q=0$ & Morimoto, $2003^{21}$ \\
\hline HT-Redox $^{d, e}$ & 200 & 72 & $100.0(1.5)$ & $\mathrm{N} / \mathrm{A}$ & -70 & Not studied & Nocera, 2004 12 \\
\hline High pressure & 450 & 24 & No defects & 4.5 & $\mathrm{~N} / \mathrm{A}$ & $120^{\circ}$ magnetic ordering, $q=0$ & Okuta, $2011^{22}$ \\
\hline High pressure & 723 & 24 & $\mathrm{~N} / \mathrm{A}$ & 4.5 & -63 & $120^{\circ}$ magnetic ordering, $q=0$ & Okubo, $2017^{23}$ \\
\hline HT-Redox $^{c}$ & 210 & 165 & $98.2(2)$ & $3.8(1)$ & -62 & $120^{\circ}$ magnetic ordering, $q=0$ & This work \\
\hline
\end{tabular}

${ }^{a}$ Authors state that they follow Dutrizac and Kaiman, 26 but no synthesis details are reported. ${ }^{b}$ Prepared by Lengauer et al. 11 , sample borrowed to Morimoto et al. 21 . ${ }^{c}$ Prepared following the hydrothermal method of Lengauer et al. 11 and details are given. ${ }^{d}$ A hydrothermal synthesis with metallic Cr. ${ }^{e}$ No detailed synthesis details have been reported for Cr-jarosite by Nocera et al. 12 to our knowledge. A,B and I,II refer to different samples in the same study.

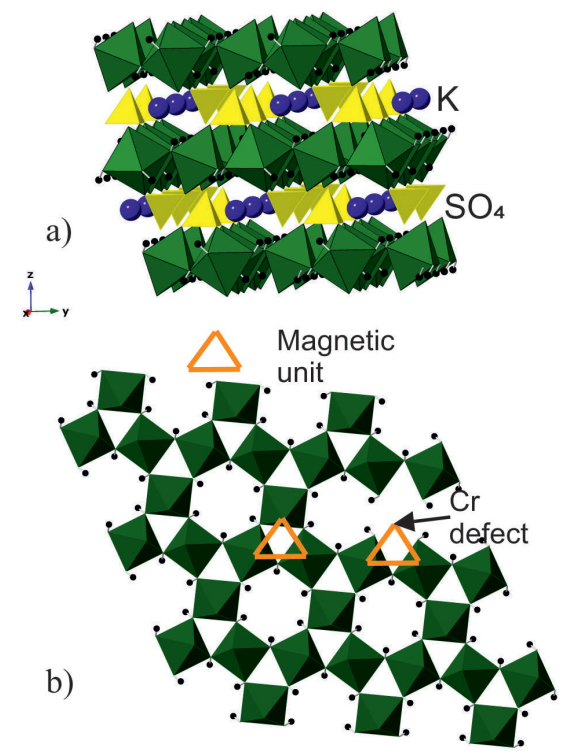

Figure 1: (a) The crystal structure of Cr jarosite. (b) The kagomé layer with the magnetic subunit shown as a triangle for a stoichiometric and a defect site. 30

However, jarosites are notorious for vacancies on the $\mathrm{M}$ site, which locally lift the magnetic frustration and result in local antiferromagnetic correlations. ${ }^{28}$ Solid state NMR studies have shown that $\mathrm{M}$ - and A-site vacancies are correlated for jarosites with $\mathrm{M}=\mathrm{Al}$, $\mathrm{Ga}, \mathrm{Fe}, \mathrm{V}$, and $\mathrm{Cr}{ }^{29}-31$ resulting in the following defect mechanism,

$$
\mathrm{M}(\mathrm{OH})_{4} \mathrm{O}_{2}+3 \mathrm{H}^{+}+\mathrm{H}_{3} \mathrm{O}^{+} \rightarrow \square^{+}\left(\mathrm{OH}_{2}\right)_{4} \mathrm{O}_{2}+\mathrm{H}_{2} \mathrm{O}+\mathrm{M}^{3+} .
$$

Thus, an $\mathrm{M}$ site vacancy, $\square$, converts four $\mathrm{M}_{2}-\mathrm{OH}$ to four $\mathrm{M}-\mathrm{OH}_{2}$ groups, as depicted in Fig. 1p. The A-site ion is replaced by a water molecule, which is not needed for charge balance. This explains the partial occupancy of alkali ions on the A-site, as confirmed by solid state NMR spectroscopy. 29,31 The presence of both $\mathrm{M}$ and A-site vacancies is closely linked to the synthesis method of choice. 19]25|29|31
The preparation of stoichiometric $\mathrm{Cr}$ jarosites is difficult and requires a slow, controlled release of $\mathrm{Cr}^{3+}$ by oxidation of elemental chromium. ${ }^{12}$ To our knowledge, neutron diffraction has been reported on Cr-jarosite samples from four different synthesis approaches, but crucial experimental details about the synthesis procedure and sample composition, including $\mathrm{Cr}$ concentration, are missing in most studies. Similarly, contradicting magnetic properties such as the observation of (and absence of) magnetic ordering as well as different magnetic ordering temperatures have been reported, c.f., Table 1. Early studies by Townsend et al. 25 , Keren et al. 18 and Lee et al. 17 all refer to the method of Dutrizac and Kaiman $\sqrt{26}$ but fail to report synthesis parameters (reagents, reaction temperature, and duration) and sample composition. We note that, Dutrizac and Kaiman ${ }^{26}$ prepared iron jarosite by heating iron and potassium sulfate in an aqueous solution under reflux conditions for a few hours and not $\mathrm{Cr}$ jarosite. Dutrizac and Chen prepared a series of $\mathrm{Cr}$ jarosite with $\mathrm{A}=\mathrm{Na}, \mathrm{K}, \mathrm{Rb}, \mathrm{Tl}, \mathrm{Ag}, \mathrm{NH}_{4}, \mathrm{H}_{3} \mathrm{O}$ and $1 / 2 \mathrm{~Pb}$ by a hydrothermal reaction at $230{ }^{\circ} \mathrm{C}$, and reported 4 $21 \%$ Cr vacancies and $11-43 \%$ A vacancies based on EDS. ${ }^{32}$ Wills reported synthesis of polycrystalline $\mathrm{Cr}$ jarosite with $81(3) \% \mathrm{Cr}$ occupancy, but no information about the K occupancy on the Asite. 24 Polycrystalline $\mathrm{Cr}$ jarosite was prepared by hydrothermal treatment by Inami et al. 19 and Morimoto et al. $\frac{21}{19}$ whereas submm sized single crystals obtained by a high pressure method (one day reaction time) were used in the most recent studies. $22[23 \mid$ These samples contained very few defects according to single crystal XRD data, albeit hydrogen species are notoriously difficult to quantify by this method. Moreover, it is also challenging to quantify a few percent defects on the $\mathrm{Cr}$ site. The conventional hydrothermal synthesis methods above leads to defect jarosite due to fast precipitation, but this can be alleviated by introducing a kinetically controlled oxidation by replacing M(III) sulfate with the corresponding metal. 16 This redox hydrothermal method was first used to successfully synthesize a variety of vanadium jarosites ${ }^{15 \mid 16}$ and iron jarosites ${ }^{14 / 33}$ including iron jarosite crystals suitable for single crystal neutron scattering studies. ${ }^{13}$ This allowed for unambiguous assessment and detailed studies of the magnetic properties. However, the properties of $\mathrm{Cr}$ jarosite were only briefly summarised in general terms by Nocera et al. ${ }^{12}$ including the mention of single crystals suitable for X-ray diffraction. However, no experimental 
data is presented there or elsewhere to our knowledge.

Most studies show evidence of a transition to a three-sublattice antiferromagnetic state, where the spins in the kagomé planes order in the $q=0$ structure with spins in a $120^{\circ}$ alignment, c.f. Table 1 17 19|21|22 However, the reported transition temperature, $T_{N}$, and Curie-Weiss temperature, $\theta_{C W}$, varies, c.f. Table 1 . The most frequently reported values for $T_{N}$ are close to $4 \mathrm{~K}$, and $\theta_{C W}$ is about $-50 \mathrm{~K}$. However, studies by Lee et al. 17 and Nocera et al. 12 showed much lower values of $\theta_{C W}(\approx-70 \mathrm{~K})$, but the latter did not observe magnetic ordering in their available temperature range down to $2 \mathrm{~K}$. The magnetic ordering has been found to be accompanied by a weak ferromagnetic moment, 19,21 which was attributed to the Dzyaloshinskii-Moriya (DM) interaction, leading to spin canting. $\frac{2334}{3}$ In contrast, Keren et al.18 observed strong dynamic spin fluctuations even at $T=25 \mathrm{mK}$ and two distinct magnetic environments. No previous study has simultaneously reported detailed, high quality data on the magnetic properties and confirmed the sample quality by detailed structural characterization.

Thus, the aim of our study is to establish the connection between the sample composition and the magnetic properties of Cr-jarosite by variation of the synthesis conditions using the redox hydrothermal method. 12 The sample quality was assessed by powder X-ray diffraction (PXRD) and solid state ${ }^{2} \mathrm{H}$ MAS NMR spectroscopy to identify crystalline impurities and the sample stoichiometry, respectively. Deuterated samples were prepared to facilitate highresolution ${ }^{2} \mathrm{H}$ MAS NMR studies ${ }^{30}$ and reduce the neutron scattering background. The sample with the least amount of $\mathrm{Cr}$ vacancies was chosen for a detailed study of the magnetic properties using susceptibility measurements and neutron diffraction.

\section{Experimental and Methods}

\subsection{Synthesis}

We employed the hydrothermal redox procedure of Grohol and Nocera $^{35}$ to prepare $\mathrm{KCr}_{3}(\mathrm{OD})_{6}\left(\mathrm{SO}_{4}\right)_{2}$, as used previously 31 except that the synthesis was scaled to $40 \mathrm{~mL}$. $1.25 \mathrm{~g}$ of $\mathrm{K}_{2} \mathrm{SO}_{4}(99.0 \%$, Sigma Aldrich) was dissolved in $14.4 \mathrm{~mL}$ of $\mathrm{D}_{2} \mathrm{O}$ (99.0\%, Cambridge Isotope Labs.) in a $50 \mathrm{~mL}$ beaker by heating the mixture to $60^{\circ} \mathrm{C}$ on a hot plate with magnetic stirring. The solution was transferred to a $40 \mathrm{~mL}$ Teflon lined hydrothermal reaction vessel, $0.6 \mathrm{~mL}$ of $18 \mathrm{M} \mathrm{H}_{2} \mathrm{SO}_{4}$ and $0.157 \mathrm{~g} \mathrm{Cr}$ pellets (99.995\%, SigmaAldrich) were added. The closed reaction vessel was placed in a Binder oven. For each temperature, the three reaction vessels were inserted in the oven so that the syntheses ended at the same time. The oven was turned off at the end of the reaction, the bombs were removed and allowed to cool at room temperature for approximately 4 hours. Visible, unreacted $\mathrm{Cr}$ metal pieces were removed before the precipitate was scraped from the Teflon container, filtered and washed with $\mathrm{D}_{2} \mathrm{O}$. The product was dried in an oven at $60{ }^{\circ} \mathrm{C}$ overnight. Three batches (denoted B1-B3) with 3 samples in each batch were synthesized with reaction temperatures of 190 , 200 , and $210{ }^{\circ} \mathrm{C}$, respectively, with reaction times spanning from $24 \mathrm{~h}$ to 7 days. The yield for the $24 \mathrm{~h}$ sample at $200{ }^{\circ} \mathrm{C}$ was too small to allow for characterization. Thus, this reaction time was replaced with a reaction time of $\approx 65 \mathrm{~h}$ for series B2 and B3. Further details about the synthesis conditions can be found in table ESI- $1^{\dagger}$.

\subsection{Powder X-Ray Diffraction}

Diffraction patterns were collected using a Bragg-Brentano setup on a BRUKER D8 Discover diffractometer and a LYNXEYE detector using $\mathrm{Cu} \mathrm{K} \alpha$ radiation. The PXRD patterns were collected in the range $10-85^{\circ}(2 \theta)$ with a stepsize of $0.02^{\circ}$. High-statistics $(8 \mathrm{~h})$ PXRD patterns were taken of six samples (B2-X and B3-X, X $=1$, 2 , and 3). Results from batch 1 originate from $1 \mathrm{~h}$ data and is therefore associated with larger uncertainties. The obtained PXRD patterns were analysed by Rietveld refinement using the Fullprof suite. $\frac{[36}{}$ The instrumental contributions to the peak width was obtained from a Si standard.

\subsection{Scanning Electron Microscopy with Energy Disper- sive Spectroscopy}

The relative concentration of $\mathrm{K}, \mathrm{Cr}$, and $\mathrm{S}$ was measured by energy dispersive X-ray spectroscopy (EDS) using a Hitachi S-4800 (Hitachi High-Technologies Corporation, Tokyo, Japan) scanning electron microscope equipped with an EDS. Approximately $1 \mathrm{mg}$ of powder was dispersed into $1 \mathrm{~mL}$ of ethanol by ultrasonification for $15 \mathrm{~min}$. A drop of the suspension was placed on a silicon wafer and then dried at $50{ }^{\circ} \mathrm{C}$ for $10 \mathrm{~min}$. Subsequently, the surface of the sample was coated with an approximately $15 \mathrm{~nm}$ layer of gold. EDS was measured in five random areas of the sample using a 15 $\mathrm{kV}$ accelerated electron beam and $15 \mathrm{~mm}$ working distance. Only samples B2-1 and B3-1 were measured.

\section{$2.4 \quad{ }^{2} \mathrm{H}$ MAS NMR spectroscopy}

Solid state ${ }^{2} \mathrm{H}$ MAS NMR spectra were recorded on a Agilent $600 \mathrm{MHz}(14.1 \mathrm{~T})$ spectrometer at ambient temperatures using a $1.6 \mathrm{~mm}$ triple resonance MAS NMR probe and spinning speeds in the range $28-33 \mathrm{kHz}$. Single pulse spectra were recorded with a short $\left(5^{\circ}\right)$ pulse, 0.1-0.2 s relaxation delay and 10,000150,000 scans per spectrum. The magic-angle was set by minimising the line width of spinning sidebands (ssb) from the ${ }^{23} \mathrm{Na}$ or ${ }^{2} \mathrm{H}$ resonance in $\mathrm{NaNO}_{3}$ and $\mathrm{CD}_{3} \mathrm{COONa}$, respectively. The ${ }^{2} \mathrm{H}$ NMR spectra were referenced relative to TMS (Tetramethylsilane) using the $\mathrm{D}_{2} \mathrm{O}\left(\delta_{\text {iso }}\left({ }^{2} H\right)=4.6 \mathrm{ppm}\right)$ as a secondary reference. The actual sample temperature in the VT spectra were estimated by using $\mathrm{Pb}\left(\mathrm{NO}_{3}\right)_{2}$ as NMR thermometer, ${ }^{37}$ see ESI-D ${ }^{\dagger}$ for further details. The ${ }^{2} \mathrm{H}$ MAS NMR spectra were processed using MestReNova (ver. 12.0.3) and analyzed using ssSnake (ver 1.2). 38 Least-square fitting of the experimental ${ }^{2} \mathrm{H}$ MAS NMR spectra included both the quadrupole interaction and the shift anisotropy, $\Delta$. Earlier reported ${ }^{2} \mathrm{H}$ NMR data were used as starting parameters. 31 We note that the main contribution to $\Delta$ is from the paramagnetic dipolar interaction as ${ }^{2} \mathrm{H}$ in inorganic materials has negligible chemical shift anisotropy $(\leq 10 \mathrm{ppm})$. The quadrupole interaction is reported as the nuclear quadrupole coupling constant,

$$
C_{Q}=\frac{e^{2} Q q Z Z}{h},
$$

and the quadrupolar asymmetry,

$$
\eta_{Q}=\frac{q_{Y Y}-q_{X X}}{q_{Z Z}}
$$

where $0 \leq \eta_{Q} \leq 1$, $e$ is the proton charge, $Q$ the nuclear quadrupole moment, and $q_{i i} \mathrm{ii}=\mathrm{xx}$, yy, and $\mathrm{zz}$ are the elements of the electric field gradient tensor. 39 The total shift tensor $(\delta)$ is reported using the Haeberlen convention,, 39 where the isotropic chemical shift is defined as

$$
\delta_{i s o}=\frac{1}{3}\left(\delta_{x x}+\delta_{y y}+\delta_{z z}\right)
$$

with the principal components ordered according to:

$$
\left|\delta_{z z}-\delta_{i s o}\right| \geq\left|\delta_{x x}-\delta_{i s o}\right| \geq\left|\delta_{y y}-\delta_{i s o}\right|
$$

The reduced anisotropy as

$$
\Delta=\delta_{z z}-\delta_{i s o}
$$


and the asymmetry parameter

$$
\eta_{\sigma}=\frac{\delta_{y y}-\delta_{x x}}{\Delta}
$$

where $0 \leq \eta_{\sigma} \leq 1$. Note that the indices $\mathrm{X}, \mathrm{Y}, \mathrm{Z}$, and $\mathrm{x}, \mathrm{y}$, $\mathrm{z}$ refer to atomic coordinates of the quadrupolar interaction and $\delta$, respectively. These two coordinate systems may not coincide and are therefore related to each other through the Euler angles $\alpha, \beta$, and $\gamma .40$

\subsection{Magnetometry}

Magnetization was measured on sample B3-1 using vibrating sample magnetometry on a Quantum Design Dynacool PPMS equipped with a 9 T DC magnet. All measurements performed are zero-field cooled (ZFC). Temperatures were varied in the range $1.7-400 \mathrm{~K}$ and magnetic fields in the range $10 \mathrm{mT}$ to $1 \mathrm{~T}$ were employed.

\subsection{Powder neutron diffraction}

Sample B3-1 was studied by powder neutron diffraction at the thermal neutron diffractometer D2041 at the Institut LaueLangevin (ILL) with neutron wavelengths of $1.87 \AA$ and $1.36 \AA$ to obtain a complete powder pattern at room temperature. ${ }^{42}$ The two datasets were refined simultaneously using Topas academic. 43

In addition, the thermal neutron triple-axis spectrometer IN3 at ILL with a wavelength of $2.36 \AA$ was used to measure the temperature evolution of the magnetic (012) reflection, which is indicative of $q=0$ antiferromagnetism in the jarosites, since the structural (012) reflection is forbidden. $\frac{19}{19}$ The intensity of this reflection will then be proportional to the square of the ordered sublattice magnetic moment, which allows for a clean measurement of the magnetic ordering. The sample was mounted in an Orange cryostat with ${ }^{4} \mathrm{He}$ exchange gas. Data was recorded from $1.5 \mathrm{~K}$ and $6.0 \mathrm{~K}$ with careful temperature control. 44 More details can be found in the supplementary information.

\section{Chemical and structural characterization}

Rietveld refinement of the PXRD diffractograms and ${ }^{2} \mathrm{H}$ MAS NMR spectroscopy was performed for all eight samples in order to select a particularly promising sample for detailed investigation of the magnetic properties.

Table 2: Refined unit cell parameters and $\mathrm{R}_{\text {Bragg }}$ values for all samples of Cr-jarosites determined from Rietveld refinement. The * indicates sample with a small amount of an unknown impurity. Two literature values given for comparison.

\begin{tabular}{llll}
\hline Sample & $\mathrm{a} / \AA$ & $\mathrm{c} / \AA$ & $\mathrm{R}_{\text {Bragg }}$ \\
\hline B1-1 & $7.2215(1)$ & $17.2124(3)$ & 11.3 \\
B1-2 & $7.2187(1)$ & $17.2341(2)$ & 11.2 \\
B2-1 & $7.2191(1)$ & $17.1886(2)$ & 6.99 \\
B2-2* & $7.2199(1)$ & $17.2205(3)$ & 7.11 \\
B2-3 & $7.2213(1)$ & $17.1866(2)$ & 5.36 \\
B3-1 & $7.2215(1)$ & $17.2343(2)$ & 7.80 \\
B3-2 & $7.2214(1)$ & $17.1822(2)$ & 5.54 \\
B3-3 & $7.2222(1)$ & $17.2119(3)$ & 5.88 \\
Grube et al. 31 & $7.229(1)$ & $17.232(9)$ & - \\
Lengauer et al. 11 & $7.2416(3)$ & 17.0788 & - \\
\hline
\end{tabular}

\subsection{Powder X-Ray Diffraction}

PXRD confirmed the formation of Cr-jarosite in all samples and showed absence of crystalline impurities, except sample B2-2 which contained a minor, unknown impurity. The diffraction patterns were analysed by Rietveld refinement, as illustrated for sample B3-1 in Fig. 2A. The results for the other seven samples are given in the supplementary information (see ESI-B ${ }^{\dagger}$ ). Close comparison of the experimental data and the calculated pattern reveals discrepancies in the fit of the Bragg peak shapes for peaks with significant $l$ contributions, evident as a shoulder and asymmetric peak shapes. The insert in Fig. 2/A compares the calculated peak shape from a bulk structure to the observed (107) peak in sample B3-1. The shape of this peak appears to vary across the sample series, without showing any clear trends, as illustrated in Fig. 23. Table 2 summarises the refined unit cell parameters for all samples. While the refined value for $a$ agrees well with earlier reported values $11|19| 21 \mid 32](\approx 7.22 \AA$ for all samples), the $c$ value varies between 17.18 and $17.23 \AA$ as compared to $17.232 \AA$ reported for a stoichiometric Cr-jarosite. ${ }^{31}$ An earlier reported values of $17.07 \AA^{11}$ is likely due to a significant concentration of $\mathrm{D}_{3} \mathrm{O}^{+}$in the structure. ${ }^{31}$ The misfit and the discrepancies between the refined $c$ parameter in the different samples indicate significant disorder in the $c$ stacking direction which is most likely due to mixed occupancy on the A-sites. Previous studies of jarosite structures have shown $\mathrm{H}_{3} \mathrm{O}^{+}$substitution of the A cation. 30]35]45/46 Here, substitution of $\mathrm{K}^{+}$with $\mathrm{D}_{3} \mathrm{O}^{+}$is likely to influence the $c$-axis length due to the differences in ionic size. However, refinements of the $\mathrm{K}$ site occupancy did not yield conclusive results, most likely due to the misfits of the affected peak shapes. In summary, the X-ray diffraction experiments reveal partial $\mathrm{D}_{3} \mathrm{O}^{+}$substitution on the $\mathrm{K}$ site and micro-structural disorder along the $c$-axis.

\subsection{SEM and EDS}

Two samples (B2-1 and B3-1) were investigated by SEM and EDS to gain insight into the particle morphology and elemental composition ( $\mathrm{S}, \mathrm{K}$ and $\mathrm{Cr}$ ). Both samples contain needle shaped particles in the ranges 2-100 $\mu \mathrm{m}$, which are agglomerates of several smaller particles (see pictures in ESI-E ${ }^{\dagger}$ ).

$\mathrm{K}: \mathrm{Cr}: \mathrm{S}$ ratios of were obtained for sample B3-1 as $\mathrm{K}: \mathrm{Cr}: \mathrm{S}=$ $0.96(3): 3.16(17): 2.00(7)$, and for sample B2-1 as $\mathrm{K}: \mathrm{Cr}: \mathrm{S}=$ $0.93(3): 3.16(17): 2.00(7)$ based on EDS analyses.

Thus, it is clear that the samples are $\mathrm{K}$ deficient and have very few $\mathrm{Cr}$ defects. Moreover, the Cr content is slightly above the ideal 3.00 , which we ascribe to the presence of unreacted $\mathrm{Cr}$ metal in the sample, as several $\mathrm{Cr}$ metal pieces were removed from the sample after filtration.

\section{$3.3 \quad{ }^{2} \mathrm{H}$ MAS NMR spectroscopy.}

The ${ }^{2} \mathrm{H}$ MAS NMR spectrum of stoichiometric $\mathrm{KCr}_{3}(\mathrm{OD})_{6}\left(\mathrm{SO}_{4}\right)_{2}$ will contain a single resonance from deuterium in a $\mathrm{Cr}_{2}-\mathrm{OD}$ environment (Fig. 1 1 1). The presence of $\mathrm{Cr}$ vacancies introduces two new sites, $\mathrm{M}-\mathrm{OD}_{2}$ and $\mathrm{D}_{2} \mathrm{O}$, c.f. Fig. 1p and Eq. (1). Moreover, one additional resonance is observed if $\mathrm{D}_{3} \mathrm{O}^{+}$substitutes $\mathrm{K}^{+}$on the A-site in stoichiometric regions of the sample, these are denoted $\mathrm{Cr}_{2}$-OD (D) and $\mathrm{Cr}_{2}$-OD (K), respectively.

The ${ }^{2} \mathrm{H}$ MAS NMR spectra contain four different sets of isotropic resonances with affiliated spinning sideband manifolds in the region $800-900 \mathrm{ppm}$ (two), $\approx 230 \mathrm{ppm}$, and $\approx 0 \mathrm{ppm}$, which are assigned to $\mathrm{Cr}_{2}-\mathrm{OD}, \mathrm{Cr}-\mathrm{OD}_{2}$, and $\mathrm{D}_{n} \mathrm{O}$ species, respectively 31 as illustrated in Figs. 3 (see ESI-D ${ }^{\dagger}$ ). The spectra of the eight samples are similar except for some variation in the relative concentration of the different species. The ${ }^{2} \mathrm{H}$ MAS NMR spectrum of B3-1 (Fig. 3) will be used as the illustrative example. The spectra from the other samples are summarized in Table 3 and in table ESI- $13^{\dagger}$. The ${ }^{2} \mathrm{H}$ MAS NMR spectrum is dominated by the spinning side band (ssb) manifold from the $\mathrm{Cr}_{2}-\mathrm{OD}(\mathrm{K})$ resonance with $\delta=821$ (3) ppm (79\% of the total intensity), which agrees well with $\delta=855.4(8)$ ppm reported recently. $\frac{31}{31}$ The resonance has a large paramagnetic shift that is caused by the Fermi-contact in- 

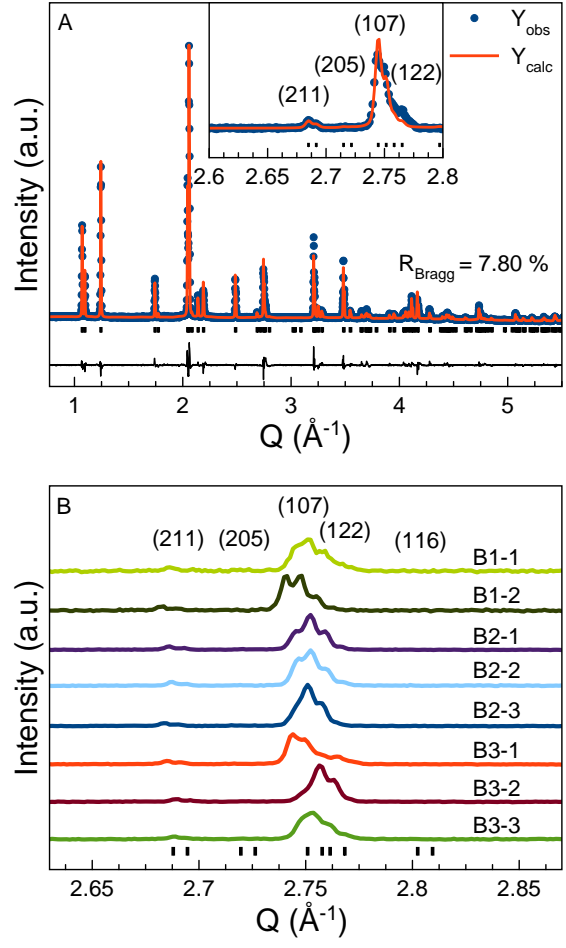

Figure 2: (A) Rietveld refinement of X-ray diffraction data on sample B3-1. The insert compares the calculated peak profile to the experimental peak profile for the (107) peak. (B) Comparison of the (107) peak for all datasets. Note that all peaks are indicated with two ticks, one for $K_{\alpha 1}$ and $K_{\alpha 2}$

teraction, i.e. the transfer of unpaired electron spin density from $\mathrm{Cr}^{3+}$ to the ${ }^{2} \mathrm{H}$ nucleus. 47 The asymmetric shape of the ssb envelope observed in these spectra is characteristic of a ${ }^{2} \mathrm{H}$ influenced paramagnetic dipolar interaction between the unpaired $d$-electrons in $\mathrm{Cr}^{3+}$ and the ${ }^{2} \mathrm{H}$ quadrupole interaction combined with the ${ }^{2} \mathrm{H}$ quadrupole interaction. 30 Closer inspection shows a shoulder located at $\delta\left({ }^{2} \mathrm{H}\right)=862(7) \mathrm{ppm}$, which constitutes about $10 \%$ of the total intensity, with a similar ssb manifold as the resonance at $\delta\left({ }^{2} \mathrm{H}\right)=821(3) \mathrm{ppm}$. This points to the presence of two, slightly different $\mathrm{Cr}_{2}$-OD environments in the samples. In our earlier study we used slower (13-14 kHz versus $30-33 \mathrm{kHz}$ ) spinning speeds leading to lower spectral resolution and possibly overlap between the $\mathrm{Cr}_{2}$-OD and $\mathrm{Cr}-\mathrm{OD}_{2}$ resonances. $\frac{31}{11}$

The ssb pattern of $\delta\left({ }^{2} \mathrm{H}\right)=862 \mathrm{ppm}$ (B3-1) matches that of the dominant resonance at $\delta\left({ }^{2} \mathrm{H}\right)=821 \mathrm{ppm}$ from the $\mathrm{Cr}_{2}$-OD in $\mathrm{Cr}$ jarosite pointing to a similar coordination environment. Thus, we assign $\delta\left({ }^{2} \mathrm{H}\right)=862$ (B3-1) to the $\mathrm{Cr}_{2}$-OD group in a small amount of $\left(\mathrm{D}_{3} \mathrm{O}\right) \mathrm{Cr}_{3}(\mathrm{OD})_{6}\left(\mathrm{SO}_{4}\right)_{2}$ present in the sample. We note that $\mathrm{Cr}_{2}$ $\mathrm{OD}$ in deuterated hydronium jarosite was earlier observed to be positioned at $827(5) \mathrm{ppm} .31$ We ascribe this $50 \mathrm{ppm}$ difference to an approximately $20{ }^{\circ} \mathrm{C}$ temperature difference in the actual sample temperature caused by frictional heating. A large temperature dependence of the isotropic shift $(-2.3 \mathrm{ppm} / \mathrm{K})$ was determined from variable temperature measurements for sample B3-1 (Fig. ESI- ${ }^{\dagger}$ ).

The resonance at $\delta=228(2) \mathrm{ppm}$ ( $6 \%$ of the total intensity) is directly coordinated to $\mathrm{Cr}$ and is assigned to $\mathrm{Cr}-\mathrm{OD}_{2}$, next to a Cr vacancy based on similar results for Fe jarosites. $\frac{30}{}$ Moreover, the spinning sideband manifold spans approximately $200 \mathrm{kHz}$ and indicate partial averaging of the quadrupolar interaction caused

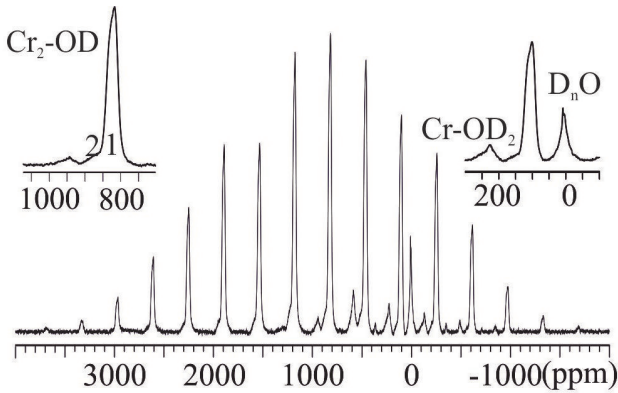

Figure 3: ${ }^{2} \mathrm{H}$ MAS NMR spectrum of sample $\mathrm{B} 3-1\left(210^{\circ} \mathrm{C}, \approx 7 \mathrm{~d}\right)$ recorded at $14.1 \mathrm{~T}$ using $32 \mathrm{kHz}$ spinning speed. The insets show the regions for the isotropic resonances. 1 and 2 marks the position for $\mathrm{Cr}_{2}-\mathrm{OD}(\mathrm{K})$ and $\mathrm{Cr}_{2}-\mathrm{OD}(\mathrm{D})$, respectively.

by rapid rotation of the $-\mathrm{OD}_{2}$ group around the $\mathrm{Cr}-\mathrm{O}$ bond vector, as also observed for jarosite,, 30 and in agreement with neutron diffraction (see below).

All samples contain an asymmetric resonance at approximately $6 \mathrm{ppm}$, which consist of two or more overlapping resonances, most probably $\mathrm{D}_{3} \mathrm{O}^{+}(\delta \approx 9 \mathrm{ppm})$ as well as $\mathrm{D}_{2} \mathrm{O}$ on the A-site and a small amount of physisorbed $\mathrm{D}_{2} \mathrm{O}(\delta \approx 5 \mathrm{ppm})$. These resonances are not directly bonded to paramagnetic $\mathrm{Cr}$ (III) and therefore only show minor paramagnetic shifts. The resonance is very sharp and the ssb's disappear quickly, again indicating high mobility of the involved species (ssb manifold spans approx. $130 \mathrm{kHz}$ ). From this, it is clear that some degree of substitution of alkali ion for water has taken place by the mechanism noted in eq. (1).

The concentration of $\mathrm{Cr}$ defects was estimated from the relative intensity of the different resonances, which must be normalized to account for different proton spin multiplicity under the assumption of isolated vacancies using the equation 2930

$$
4 x=6 \frac{\frac{1}{2} I\left(\mathrm{Cr}-\mathrm{OD}_{2}\right)}{I\left(\mathrm{Cr}_{2}-\mathrm{OD}\right)+\frac{1}{2} I\left(\mathrm{Cr}-\mathrm{OD}_{2}\right)} .
$$

The factor of 4 is due to the four OD sites affected per Cr vacancy, whereas the factor 6 refers to the total of six OD groups present in $\mathrm{KCr}_{3}(\mathrm{OD})_{6}\left(\mathrm{SO}_{4}\right)_{2}$. In the following, the $\mathrm{Cr}-\mathrm{OD}_{2}$ includes both the $\mathrm{Cr}_{2}-\mathrm{OD}(\mathrm{D})$ and $\mathrm{Cr}_{2}-\mathrm{OD}(\mathrm{K})$ environments, since they are presumed to originate from a single jarosite phase, $\left[\mathrm{K}_{1-\mathrm{x}}\left(\mathrm{D}_{\mathrm{n}} \mathrm{O}\right)_{\mathrm{y}}\right] \mathrm{Cr}_{3-\mathrm{x}}\left(\mathrm{SO}_{4}\right)_{2}(\mathrm{OD})_{6-4 \mathrm{x}}\left(\mathrm{OD}_{2}\right)_{4 \mathrm{x}}$, thus yielding a bulk composition of the sample, c.f., Table 3 . Thus, the samples contain only $1-3 \% \mathrm{Cr}$ vacancies, values nearly impossibly to quantify by diffraction, and confirm the formation of a nearly ideal kagomé lattice. The average number $(n)$ of deuterons on the potassium site is estimated using:

$$
n=6 \frac{I\left(\mathrm{D}_{\mathrm{n}} \mathrm{O}\right)}{I\left(\mathrm{Cr}_{2}-\mathrm{OD}\right)+\frac{1}{2} I\left(\mathrm{Cr}-\mathrm{OD}_{2}\right)} .
$$

The results of the analysis are found in Table 3 . For the analysis of the water content a value of $n=3, n=2$ and $n=0$ corresponds to the A-site being occupied fully by $\mathrm{D}_{3} \mathrm{O}^{+}, \mathrm{D}_{2} \mathrm{O}$, and $\mathrm{K}^{+}$respectively. $n$ values of $\approx 0.1$ to 0.6 are obtained (Table 3 ) corresponding to $2-27 \% \mathrm{D}_{n} \mathrm{O}$ species on the A-site. For B3-1, this gives an approximate $\mathrm{K}^{+}$occupancy with a lower boundary of about $84 \%$ and an upper boundary of $89 \%$, for either $\mathrm{D}_{2} \mathrm{O}$ or $\mathrm{D}_{3} \mathrm{O}^{+}$on the A-site, respectively, in good agreement with the neutron diffraction data and EDS. Thus, from ${ }^{2} \mathrm{H}$ MAS NMR the samples contain a very small (1-3\%) amount of Cr vacancies, whereas significant (2-27\%) substitution of $\mathrm{K}$ with mainly $\mathrm{D}_{3} \mathrm{O}^{+}$is observed. 
Table 3: $\delta_{i s o}\left({ }^{2} \mathrm{H}\right)$ for the different environments recorded at $33 \mathrm{kHz}$ spinning speed. The water content and Cr-site vacancies in the different samples were studied by fitting of the recorded ${ }^{2} \mathrm{H}$ MAS NMR spectra (see Fig. ESI- $2^{\dagger}$ ). The intensity percentages are given after the peak position in parentheses(see Fig. ESI- $3^{\dagger}$ for a visual representation). The peak position errors were estimated from the standard deviation of the average $\delta_{i s o}\left({ }^{2} \mathrm{H}\right)$ values. All shifts are given in ppm. Vacancies are given per mol.

\begin{tabular}{|c|c|c|c|c|c|c|c|c|}
\hline Sample & $\delta_{i s o}\left(\mathrm{Cr}_{2}-\mathrm{OD}(\mathrm{D})\right)$ & $\delta_{i s o}\left(\mathrm{Cr}_{2}-\mathrm{OD}(\mathrm{K})\right.$ & $\delta_{\text {iso }}\left(\mathrm{Cr}-\mathrm{OD}_{2}\right)$ & $\delta_{\text {iso }}\left(\mathrm{D}_{n} \mathrm{O}\right)$ & $x$ & $\mathrm{Cr}^{3+}$ vacancies & $n$ & $\mathrm{~K}^{+}$vacancies \\
\hline$\overline{\mathrm{B} 1-1}$ & $876(7)(9 \%)$ & $828(3)(76 \%)$ & $230(2)(7 \%)$ & $7(1)(8 \%)$ & $0.056(5)$ & $1.9(2) \%$ & $0.55(7)$ & $\sim 18-27 \%$ \\
\hline B1-2 & $876(7)(13 \%)$ & $828(3)(77 \%)$ & $230(2)(9 \%)$ & $7(1)(1 \%)$ & $0.071(5)$ & $2.4(2) \%$ & $0.07(7)$ & $\sim 2-4 \%$ \\
\hline B2-1 & $864(7)(15 \%)$ & $823(3)(73 \%)$ & $226(2)(8 \%)$ & $6(1)(4 \%)$ & $0.068(5)$ & $2.3(2) \%$ & $0.28(7)$ & $\sim 9-14 \%$ \\
\hline B2-2 & $860(7)(18 \%)$ & $822(3)(64 \%)$ & $226(2)(11 \%)$ & $6(1)(7 \%)$ & $0.091(4)$ & $3.0(1) \%$ & $0.46(6)$ & $\sim 16-23 \%$ \\
\hline B2-3 & $865(7)(19 \%)$ & $823(3)(63 \%)$ & $228(2)(11 \%)$ & $5(1)(7 \%)$ & $0.090(4)$ & $3.0(1) \%$ & $0.49(6)$ & $\sim 16-25 \%$ \\
\hline B3-1 & $862(7)(10 \%)$ & $821(3)(79 \%)$ & $228(2)(6 \%)$ & $5(1)(5 \%)$ & $0.053(5)$ & $1.8(2) \%$ & $0.32(7)$ & $\sim 11-16 \%$ \\
\hline B3-2 & $870(7)(19 \%)$ & $827(3)(63 \%)$ & $230(2)(11 \%)$ & $8(1)(7 \%)$ & $0.095(4)$ & $3.2(1) \%$ & $0.49(6)$ & $\sim 16-24 \%$ \\
\hline
\end{tabular}

Note: Spectra for samples B1-1 and B1-2 were recorded on a different spectrometer (11.7 T) with lower spinning speed, i.e. sample temperature, and a higher degree of overlap between the $\mathrm{Cr}-\mathrm{OD}_{2}$ and $\mathrm{D}_{2} \mathrm{O} / \mathrm{D}_{3} \mathrm{O}^{+}$resonances, which lead to a less precise analyses. The temperature dependence of the isotopic shift is reported in Fig. ESI-4 ${ }^{\dagger}$.

\section{Structural and magnetic characterization of one selected sample}

Sample B3-1 was selected for a detailed investigation of the magnetic properties using magnetometry and neutron diffraction, as this was deemed to have the most intact magnetic lattice with 98.2(2)\% Cr occupancy. Overall, it was one of the most stoichiometric samples with $84-89 \% \mathrm{~K}$ occupancy. However, it is clear that the samples are quite similar with respect to $\mathrm{Cr}$ defect concentration and A-site occupancy within the experimental uncertainties.

\section{1 magnetization and susceptibility}

Vibrating sample magnetometry was performed on sample B3-1 in the temperature range 1.7 to $400 \mathrm{~K}$ in applied magnetic fields, $H$, ranging from 100 to 10,000 Oe to gain insight into the magnetic properties. In the paramagnetic phase, the susceptibility can be extracted from the measured magnetization, $M$, as $\chi=M / H$. Fig. 4h shows the reciprocal molar susceptibility, $\chi^{-1}$, versus temperature in an applied field of 10,000 Oe. $\chi^{-1}$ is linear at high temperatures, but deviations from a linear behaviour is observed below $\sim 100 \mathrm{~K}$. The high-temperature data was fitted to a CurieWeiss law, $\chi=C /\left(T-\theta_{\mathrm{CW}}\right)$, using a $g$-factor of $g=1.97$ obtained by electron spin resonance measurements. $\frac{23}{23}$ This yields a CurieWeiss temperature of $\theta_{C W} \approx-62 \mathrm{~K}$. At roughly $4 \mathrm{~K}$, the reciprocal susceptibility suddenly changes, indicative of an antiferromagnetic ordering. The phase transition was studied in detail at low temperatures in a small applied magnetic field of 100 Oe (Fig. 4p). A small spontaneous magnetic moment appears below $\sim 4 \mathrm{~K}$, indicating an antiferromagnetic phase transition with a slightly canted moment. The data show clear hysteresis loops, as illustrated in Fig. 4k, which progressively become smaller as the temperature is increased. At $4 \mathrm{~K}$ the magnetization curve is linear, corresponding to a phase transition in the region between $T=3.5 \mathrm{~K}$ and $T=4 \mathrm{~K}$. The loops show a zero-field remnant magnetization of $\approx 0.025 \mu_{B} / \mathrm{Cr}^{3+}$ at low temperatures, which is less than $1 \%$ of the magnetic moment for Cr(III) in an octahedral ligand field $\left(3.87 \mu_{B}\right)$. This is in agreement with an antiferromagnetically ordered phase with slightly canted spins below $T_{N}$ most likely due to a pronounced DM interaction in Cr-jarosite. $23 \mid 34$

\subsection{Room temperature powder neutron diffraction}

Further insight into the crystal structure and the $\mathrm{D}_{3} \mathrm{O}^{+}$-substitution was obtained from room temperature neutron powder diffraction on sample B3-1 as seen in Fig. 5. In addition to the diffraction pattern from the jarosite sample, the powder neutron diffraction (NPD) data also contain a large contribution from the aluminum sample holder which was modeled through a Le Bail re-
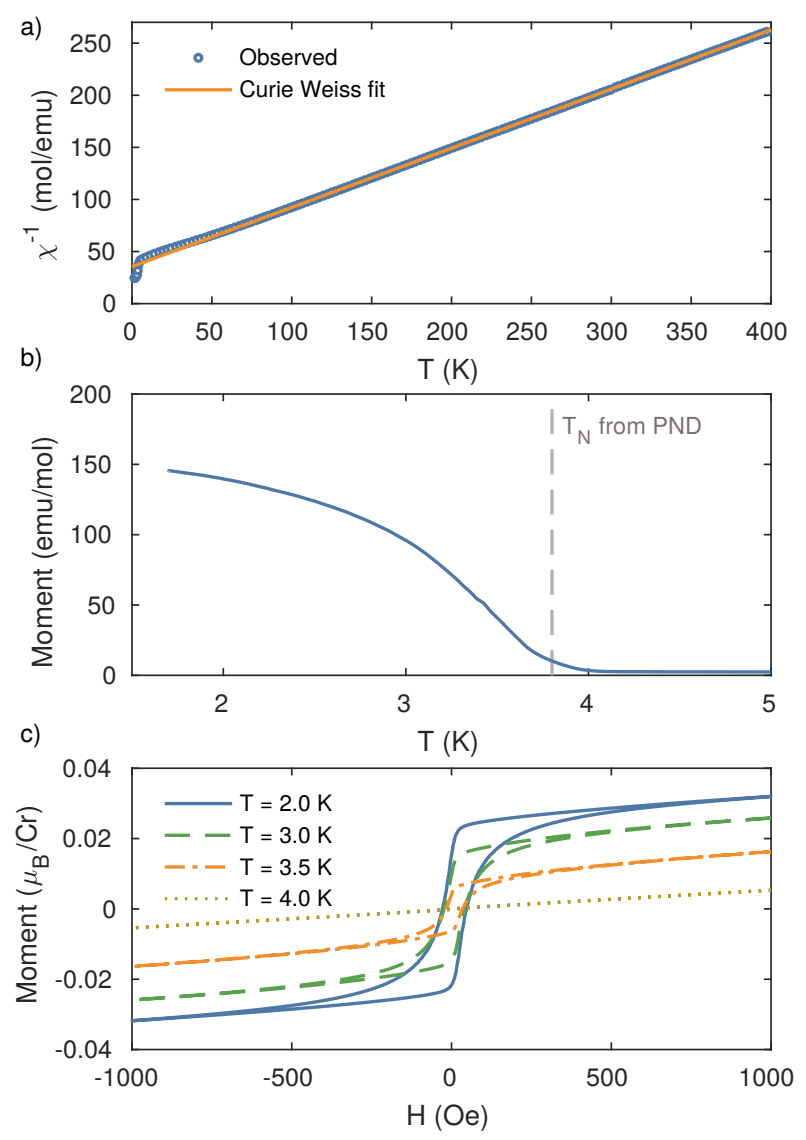

Figure 4: (a) Temperature dependence of the reciprocal susceptibility of sample B3-1 in a 10,000 Oe field. (b) Temperature dependence of the magnetization in sample B3-1 in 100 Oe. Dashed grey line indicates $T_{N}$ obtained via PND. (c) Hysteresis curves for sample B3-1 at four different temperatures. The hysteresis has disappeared at $T=4 \mathrm{~K}$.

finement. Rietveld refinement of the two NP data sets $(\lambda=1.87 \AA$ and $\lambda=1.36 \AA$ ) collected from sample B3-1 is shown in Fig. 5 . The model obtained from PXRD refinements resulted in $\mathrm{R}_{\text {Bragg }}$ values of $8.11 \%$ for the data set measured with $\lambda=1.87 \AA$ and $5.01 \%$ for the dataset measured with $\lambda=1.36 \AA$, which indicates that it only described the overall structure. In addition, the Atomic Displacement Parameters (ADP) values for OD group attached to $\mathrm{Cr}$ 
furthermore refined to unphysical negative values.
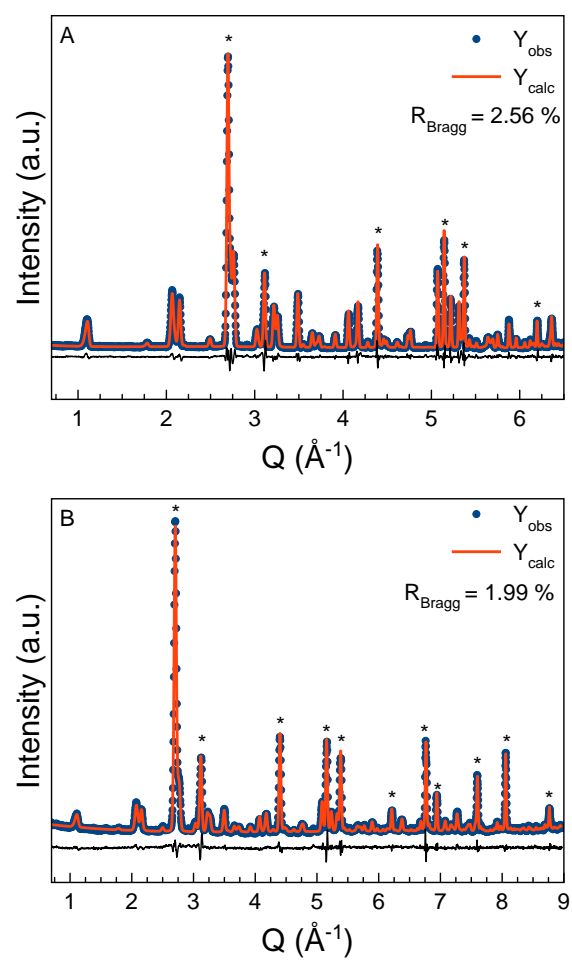

Figure 5: Simultaneous Rietveld refinements of the two neutron diffractograms from sample B3-1 measured with wavelengths of $1.87 \AA(\mathrm{A})$ and $1.36 \AA(\mathrm{B})$. The resulting model shows around $90 \%$ $\mathrm{K}$ on the A site and a large degree of disorder at the OD groups. * indicate peaks from the $\mathrm{Al}$ sample holder

As discussed earlier, ${ }^{2} \mathrm{H}$ MAS NMR results suggested that both $\mathrm{OD}$ and $\mathrm{OD}_{2}$ species are present on the crystallographic $\mathrm{O}(\mathrm{H})$ sites. Furthermore, the $\mathrm{OD}_{2}$ rotates rapidly around the $\mathrm{Cr}-\mathrm{O}$ bond vector at room temperature spreading out the nuclear density of the OD and $\mathrm{OD}_{2}$ groups. Thus, the ADPs for the deuterium and oxygen bonded to chromium were refined anisotropically to account for this effect. This greatly improved the fit and reduced the $\mathrm{R}_{\mathrm{Bragg}}$ values from $8.11 \%$ to $4.42 \%$ for the $1.87 \AA$ measurement and from $5.01 \%$ to $2.83 \%$ for the $1.36 \AA$ measurement. By further refining the occupancy of $\mathrm{K} / \mathrm{D}_{3} \mathrm{O}^{+}$on the $\mathrm{K}$ site and of deuterium in the OD groups, the fits were improved and provided physical values for the ADP parameters that are consistent with the NMR results. The $\mathrm{R}_{\mathrm{Bragg}}$ was reduced from from $4.42 \%$ to $2.56 \%$ and from $2.83 \%$ to $1.99 \%$ for the $1.87 \AA$ and $1.36 \AA$ measurements, respectively. The model suggests approximately $10 \%$ occupancy of $\mathrm{D}_{3} \mathrm{O}^{+}$and $90 \%$ $\mathrm{K}$ occupancy at the $(0,0,0)$ position and around $50 \%$ occupancy of $\mathrm{D}$ in the the OD groups. The A-site occupancy is in excellent agreement with EDS and NMR, whereas the OD occupancy is too low based on NMR, most likely due to the pronounced disorder along the crystallographic $c$-axis. The final fits are seen in Fig. 5 and all results are given in the supplementary information. The anisotropic ADPs of the OD deuterium are very large in the a/bplane, suggesting that the nuclear density is spread out in the space between the $\mathrm{K}^{+}$and $\mathrm{SO}_{4}^{2-}$ ions. The occupancy and large ADP values reflect significant rotation (disorder) of the $\mathrm{OD}$ and $\mathrm{OD}_{2}$ groups that are coordinated to the $\mathrm{Cr}$.

\subsection{Temperature-dependent powder neutron diffrac- tion}

The low-temperature neutron diffraction data was obtained in the Q range from 1.00 to $1.35 \AA^{-1}$, i.e., in the region for the structural (003) and purely magnetic (012), which is a signature of a $q=0$ magnetic order. ${ }^{19}$ The temperature evolution of the peak intensity is illustrated in Fig. 6. The intensity increases from background level at high temperatures to a plateau below $3 \mathrm{~K}$.

Fitting the neutron diffraction data to a power law, $I=I_{0}(1-$ $\left.T / T_{\mathrm{N}}\right)^{2 \beta}+\mathrm{bkg}$, in the critical region above $3 \mathrm{~K}$ yields a value for the ordering temperature of $T_{\mathrm{N}}=3.8(1) \mathrm{K}$ and a critical exponent of $\beta=0.3(1)$. This value of $T_{\mathrm{N}}$ is consistent with the magnetization measurements, c.f., Fig. 4 In addition, the obtained $T_{\mathrm{N}}$ agrees with the disappearance of hysteresis between $T=3.5 \mathrm{~K}$ and $T=4 \mathrm{~K}$ in Fig. 4. The critical exponent value for a magnetic phase transition can in general link the system under study to a universality class. Our value of $\beta=0.3(1)$ match a number of likely universality classes, such as $\beta=0.36$ for a 3D Heisenberg system, and $\beta=0.25$ for a $2 \mathrm{D}$ chiral XY system. ${ }^{48}$ A more precise determination of the critical exponents would require much higher quality data, e.g. from single crystal diffraction, which is beyond the scope of the present study. All this points towards a conventional three-

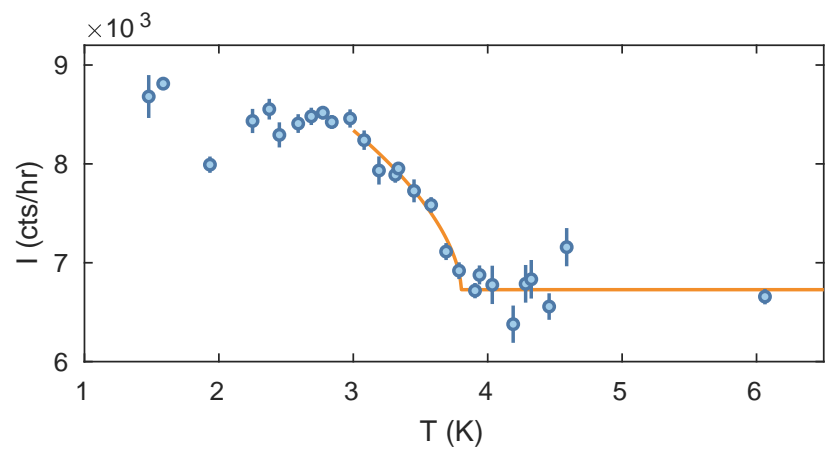

Figure 6: Temperature dependence of the intensity of the (012) magnetic peak as measured by powder neutron diffraction. The fit is a power law to the critical region as described in the text.

dimensional long-ranged order in Cr-jarosite. Combined with the value $\theta_{\mathrm{CW}}=-62 \mathrm{~K}$ from susceptibility, this provides a frustration index for K-Cr-jarosite of $f=\left|\theta_{C W}\right| / T_{N} \approx 16$, which for our $S=3 / 2$ system is only slightly higher than the value $f \approx 12$ for the more common $S=5 / 2$ system K-Fe-jarosite $\left(\mathrm{KFe}_{3}(\mathrm{OH})_{6}\left(\mathrm{SO}_{4}\right)_{2}\right) .13$ Taken together, our findings point towards the lack of prominent quantum effects that could hypothetically arise from the lower spin value of Cr-jarosite. Instead, this system behaves as a frustrated, classical magnet.

\subsection{Discussion}

A comparison of our results with literature is summarized in Table 1. A number of studies find values of $T_{\mathrm{N}}$ in the range $4.0 \mathrm{~K}$ to $4.2 \mathrm{~K}$, in agreement with our data. 19.21 More recent studies find a slightly higher value $(4.5 \mathrm{~K}) \cdot \sqrt{22 \sqrt{23}}$ However, none of these works quantify the levels of impurities or vacancies. This could lead to doubt on whether the observed clear 3D ordering was, in fact, caused by defects lifting the frustration. In contrast, samples prepared with reported $100 \%$ Cr occupancy display much lower values of $T_{\mathrm{N}}(<2 \mathrm{~K})$ or no ordering above $2 \mathrm{~K} \cdot 12[17$ However, our B3-1 sample, which has a quantified, low content of $\mathrm{Cr}$ vacancies and $85-95 \% \mathrm{~K}$ occupancy orders at $3.8 \mathrm{~K}$ consistent with most lit- 
erature values. Therefore, it seems safe to conclude that the magnetic ordered state in Cr-jarosite, which has an ordering temperature around $4 \mathrm{~K}$, is an intrinsic property of the material and not caused by $\mathrm{Cr}$ vacancies. Interestingly, our values for $T_{\mathrm{N}}$ and $\theta_{\mathrm{CW}}$ differ significantly from those reported by Lee et al.17 and Nocera et al.12. We speculate that the large discrepancies may stem from $\mathrm{D}_{3} \mathrm{O}$ substitution on the A-site, as hydronium-iron-jarosite, $\mathrm{D}_{3} \mathrm{OFe}_{3}(\mathrm{OH})_{6}\left(\mathrm{SO}_{4}\right)_{2}$, display spin glass behaviour. $\frac{49}{}$ The substitution of $\mathrm{K}^{+}$for $\mathrm{D}_{3} \mathrm{O}$ in Cr-jarosite could also be responsible for suppressing $T_{\mathrm{N}}$ in the earlier works. However, the magnetic properties of hydronium $\mathrm{Cr}$ jarosite are not understood in full detail.24

\section{Conclusions}

Eight Cr-jarosites (ideally $\left.\mathrm{KCr}_{3}(\mathrm{OD})_{6}\left(\mathrm{SO}_{4}\right)_{2}\right)$ prepared by the redox hydrothermal procedure were characterized by powder X-ray diffraction, neutron diffraction, solid state NMR spectroscopy, and scanning electron microscopy with energy dispersive spectroscopy, which provided novel insight into this material, including detailed quantification of $\mathrm{Cr}$ vacancies and species on the A-site $\left(\mathrm{K}, \mathrm{D}_{2} \mathrm{O}\right.$, and $\mathrm{D}_{3} \mathrm{O}^{+}$). PXRD confirmed the formation of Cr-jarosite, but also revealed significant, complex stacking disorder along the $c$ axis due to mixed $\mathrm{K}$ and $\mathrm{D}_{n} \mathrm{O}$ occupancy on the A-site, evident mainly in the reflections with high $l$ values, e.g., (107). ${ }^{2} \mathrm{H}$ MAS NMR showed a nearly ideal magnetic lattice with only $1-3 \%$ of $\mathrm{Cr}$ vacancies for all samples, but also clearly showed that the A-site has a significant concentration of $\mathrm{D}_{3} \mathrm{O}^{+}$and/or $\mathrm{D}_{2} \mathrm{O}$. The magnetic properties of the best sample $(98.8(2) \% \mathrm{Cr}$ and $84-89 \% \mathrm{~K}$ occupancy) were investigated in detail by magnetization , susceptibility, and powder neutron diffraction. The Curie-Weiss temperature $\theta_{C W}=-62 \mathrm{~K}$ was determined from susceptibility data. magnetization and neutron diffraction consistently yielded $T_{\mathrm{N}}=3.8(1) \mathrm{K}$, and the position of the magnetic diffraction signal was consistent with an antiferromagnet with a 3 -sublattice $\left(120^{\circ}\right)$ state. However, a small ferromagnetic moment $\left(\sim 1 \%\right.$ of the free $\left.\mathrm{Cr}^{3+}\right)$ was observed below $T_{\mathrm{N}}$. This spin canting, previously reported in literature, is caused by the Dzyaloshinskii-Moriya interaction, also observed in iron jarosite. 13

Our value of the magnetic ordering temperature agrees with a large fraction of values reported in literature. However, since the chemical composition of our sample is known, we believe that our value $T_{\mathrm{N}}=3.8 \mathrm{~K}$ is a reliable estimate for the pure Cr-jarosite system, removing the last doubt about the ordering temperature of this material. The value of the frustration index, $f \sim 16$ is only slightly higher than that of iron jarosite and therefore our results point to a stable 3-dimensional magnetic order without signs of quantum effects.

\section{Conflicts of interest}

The authors declare no conflict of interest.

\section{Acknowledgements}

We would like to thank Mr Christian B. Jørgensen, SDU for assistance with NMR measurements, Dr. Tae-Hyun Kim for SEM-EDS measurements, Dr. Thomas Hansen ILL, for performing the neutron diffraction measurements at D20, and Dr. Monica JiménezRuiz, ILL, for help with preparations for the neutron experiments. The project was supported by the Danish Council for Independent Research (DFF-7014-00198; UGN; ABAA, MBS) and by the Danish Agency for Research and Innovation through DANSCATT. The 600 $\mathrm{MHz}$ NMR spectrometer is part of the Villum Center for Bioanalytical Analyses. M.J. and K.M.Ø.J are grateful for funding from the Villum Foundation through a Villum Young Investigator Grant. K.S.P. thanks the VILLUM Foundation for a VILLUM Young Investi- gator grant (15374), and the Carlsberg Foundation (CF-17-0637) for a research infrastructure grant.

\section{Notes and references}

[1] J. T. Chalker, in Geometrically Frustrated Antiferromagnets: Statistical Mechanics and Dynamics, ed. C. Lacroix, P. Mendels and F. Mila, Springer, Berlin, Heidelberg, 2011, pp. 3-22.

[2] L. Savary and L. Balents, Reports on Progress in Physics, 2017, 80, 016502.

[3] Y. Zhou, K. Kanoda and T. K. Ng, Rev. Mod. Phys., 2017, 89, 025003.

[4] A. Chubukov, Physical Review Letters, 1992, 69, 832-835.

[5] S. Sachdev, Physical Review. B, 1992, 45, 12377-12396.

[6] A. B. Harris, C. Kallin and A. J. Berlinsky, Physical Review B, 1992, 45, 28992919.

[7] P. Mendels and A. S. Wills, in Kagomé Antiferromagnets: Materials Vs. Spin Liquid Behaviors, ed. C. Lacroix, P. Mendels and F. Mila, Springer, Berlin, Heidelberg, 2011, pp. 207-238.

[8] J. Wen, S.-L. Yu, S. Li, W. Yu and J.-X. Li, npj Quantum Materials, 2019, 4, 12.

[9] D. E. Freedman, T. H. Han, A. Prodi, P. Müller, H. Qing-Zhen, Y.-S. Chen, S. M. Webb, Y. S. Lee, T. M. McQueen and D. G. Nocera, Journal of the American Chemical Society, 2010, 132, 16185âĂŞ16190.

[10] N. Jiang, A. Ramanathan, J. Bacsa and H. S. La Pierre, Nat. Chem., 2020, 12, 691-696.

[11] C. L. Lengauer, G. Giester and E. Irran, Powder Diffraction, 1994, 9, 265-271.

[12] D. G. Nocera, B. M. Bartlett, D. Grohol, D. Papoutsakis and M. P. Shores, Chemistry - A European Journal, 2004, 10, 3850-3859.

[13] D. Grohol, K. Matan, J.-H. Cho, S.-H. Lee, J. W. Lynn, D. G. Nocera and Y. S. Lee, Nature Materials, 2005, 4, 323-328.

[14] B. M. Bartlett and D. G. Nocera, Journal of the American Chemical Society, 2005, 127, 8985-8993.

[15] D. Papoutsakis, D. Grohol and D. G. Nocera, Journal of the American Chemical Society, 2002, 124, 2647-2656.

[16] D. Grohol and D. G. Nocera, Journal of the American Chemical Society, 2002, 124, 2640-2646.

[17] S.-H. Lee, C. Broholm, M. F. Collins, L. Heller, A. P. Ramirez, C. Kloc, E. Bucher, R. W. Erwin and N. Lacevic, Physical Review B, 1997, 56, 8091-8097.

[18] A. Keren, K. Kojima, L. P. Le, G. M. Luke, W. D. Wu, Y. J. Uemura, M. Takano, H. Dabkowska and M. J. P. Gingras, Physical Review B, 1996, 53, 6451-6454.

[19] T. Inami, T. Morimoto, M. Nishiyama, S. Maegawa, Y. Oka and H. Okumura, Physical Review B, 2001, 64, 054421.

[20] M. Nishiyama, T. Morimoto, S. Maegawa, T. Inami and Y. Oka, Canadian Journal of Physics, 2001, 79, 1511-1516.

[21] T. Morimoto, M. Nishiyama, S. Maegawa and Y. Oka, Journal of the Physical Society of Japan, 2003, 72, 2085-2090.

[22] K. Okuta, S. Hara, H. Sato, Y. Narumi and K. Kindo, Journal of the Physical Society of Japan, 2011, 80, 063703

[23] S. Okubo, R. Nakata, S. Ikeda, N. Takahashi, T. Sakurai, W.-M. Zhang, H. Ohta, T. Shimokawa, T. Sakai, K. Okuta, S. Hara and H. Sato, Journal of the Physical Society of Japan, 2017, 86, 024703

[24] A. S. Wills, PhD thesis, The University of Edinburgh, 1996.

[25] M. G. Townsend, G. Longworth and E. Roudaut, Physical Review B, 1986, 33 , 4919-4926.

[26] J. E. Dutrizac and S. Kaiman, Canadian Mineralogist, 1976, 14, 151-158.

[27] R. J. Cava, K. L. Holman, T. McQueen, E. J. Welsh, D. V. West and A. J. Williams in The Geometries of Triangular Magnetic Lattices, ed. C. Lacroix, P. Mendels and F. Mila, Springer, Berlin, Heidelberg, 2011, pp. 131-154.

[28] U. G. Nielsen, I. Heinmaa, A. Samoson, J. Majzlan and C. P. Grey, Chemistry of Materials, 2011, 23, 3176-3187. 
[29] U. Nielsen, J. Majzlan, B. Phillips, M. Ziliox and C. Grey, The American Mineralogist, 2007, 92, 587-597.

[30] U. G. Nielsen, J. Majzlan and C. P. Grey, Chemistry of Materials, 2008, 20, 2234 2241.

[31] E. Grube, A. Lipton and U. Nielsen, Physics and Chemistry of Minerals, 2019, 46, 299-309.

[32] J. E. Dutrizac and T. Chen, Canadian Metallurgical Quarterly, 2006, 45, 249260.

[33] D. Grohol, D. G. Nocera and D. Papoutsakis, Physical Review B, 2003, 67, 064401.

[34] M. Elhajal, B. Canals and C. Lacroix, Physical Review B, 2002, 66, 1-6.

[35] D. Grohol and D. G. Nocera, Chemistry of Materials, 2007, 19, 3061-3066.

[36] J. Rodríguez-Carvajal, Physica B, 1993, 192, 55 - 69.

[37] A. Bielecki and D. P. Burum, Journal of Magnetic Resonance, Series A, 1995, 116, 215-220.

[38] S. W. Franssen and A. Kentgens, Journal of Magnetic Resonance, 2019, 301, 56 $-66$

[39] R. Harris, E. Becker, S. De Menezes, P. Granger, R. Hoffman and K. Zilm, Magnetic Resonance in Chemistry, 2008, 46, 582-598.

[40] J. Skibsted, N. C. Nielsen, H. Bildsøe and H. J. Jakobsen, Chemical Physics Letters, 1992, 188, 405-412.

[41] T. C. Hansen, P. F. Henry, H. E. Fischer, J. Torregrossa and P. Convert, Measurement Science and Technology, 2008, 19, 034001.

[42] DOI for ILL data from D20, 2019, doi.ill.fr/10.5291/ILL-DATA.EASY-458.

[43] A. A. Coelho, Journal of Applied Crystallography, 2018, 51, 210-218.

[44] DOI for ILL data from IN3, 2019, doi.ill.fr/10.5291/ILL-DATA.TEST-3020.

[45] A. Harrison, A. Wills and C. Ritter, Physica B, 1997, 241-243, 722 - 723.

[46] A. S. Wills, A. Harrison, C. Ritter and R. I. Smith, Phys. Rev. B, 2000, 61, 61566169.

[47] C. P. Grey, G. Pintacuda and A. J. Pell, Progress in Nuclear Magnetic Resonance, 2019, 111, 1-271.

[48] M. F. Collins and O. A. Petrenko, Can. J. Phys., 1997, 75, 605-655.

[49] A. Wills, A. Harrison, S. A. M. Mentink, T. E. Mason and Z. Tun, Europhysics Letters, 1998, 42, 325. 
Electronic Suppelementary Information for Structural characterization and magnetic properties of chromium jarosite $\mathrm{KCr}_{3}(\mathrm{OD})_{6}\left(\mathrm{SO}_{4}\right)_{2}$

Sofie Janas ${ }^{a b}$, Mathilde B. Sørensen ${ }^{a}$, Anders B. A. Andersen ${ }^{c}$, Mikkel Juelsholt ${ }^{f}$, Martin Boehm $^{d}$, Kasper S. Pedersen ${ }^{e}$, Kirsten M. Ø. Jensen ${ }^{f}$, Kim Lefmann $^{a}$, Ulla Gro Nielsen ${ }^{c}$

${ }^{a}$ Niels Bohr Institute, University of Copenhagen, DK-2100 Copenhagen Ø, Denmark.

${ }^{b}$ Laboratory for Quantum Magnetism, Institute of Physics, EPFL, 1015 Lausanne, Switzerland.

${ }^{c}$ Institute of Physics, Chemistry, and Pharmacy, University of Southern Denmark, Campusvej 55, 5230 Odense M, Denmark.

E-mail: ugn@sdu.dk

${ }^{d}$ Institut Max von Laue Paul Langevin, 38042 Grenoble, France.

${ }^{e}$ Institute of Chemistry, Technical University of Denmark, DK-2800 Kgs. Lyngby, Denmark.

${ }^{f}$ Department of Chemistry and Nano-Science Center, University of Copenhagen, DK-2100 Copenhagen $\emptyset$, Denmark.

\section{Contents}

ESI-A Synthesis details

ESI-B Rietveld refinement of PXRD data for remaining samples

ESI-C Rietveld refinement of powder neutron diffraction

5

ESI-D Additional ${ }^{2} \mathrm{H}$ MAS NMR data

ESI-E Scanning Electron microscopy of selected samples 


\section{ESI-A Synthesis details}

Synthesis details of all samples are shown in table ESI-1, ESI-A.

Table ESI-1: Synthesis detail for all prepared samples. All syntheses were carried out in 40 mL hydrothermal reaction vessels, see synthesis section in main article for further details.

\begin{tabular}{lrrr}
\hline Batch 1 & & & \\
Sample & $\mathrm{B} 1-1$ & $\mathrm{~B} 1-2$ & $\mathrm{~B} 1-3$ \\
\hline Yield & $0.168 \mathrm{~g}$ & $0.239 \mathrm{~g}$ & $0.022 \mathrm{~g}$ \\
Percent theoretical yield & $34.1 \%$ & $48.5 \%$ & $4.5 \%$ \\
Temperature & $200{ }^{\circ} \mathrm{C}$ & $200{ }^{\circ} \mathrm{C}$ & $200{ }^{\circ} \mathrm{C}$ \\
Synthesis time & $165.5 \mathrm{~h}$ & $94 \mathrm{~h}$ & $24 \mathrm{~h}$ \\
\hline Batch 2 & & & \\
Sample & $\mathrm{B} 2-1$ & $\mathrm{~B} 2-2$ & $\mathrm{~B} 2-3$ \\
\hline Yield & $0.2403 \mathrm{~g}$ & $0.2839 \mathrm{~g}$ & $0.1954 \mathrm{~g}$ \\
Percent theoretical yield & $48.7 \%$ & $57.6 \%$ & $40.0 \%$ \\
Temperature & $190{ }^{\circ} \mathrm{C}$ & $190{ }^{\circ} \mathrm{C}$ & $190{ }^{\circ} \mathrm{C}$ \\
Synthesis time & $164 \mathrm{~h}$ & $95 \mathrm{~h}$ & $65 \mathrm{~h}$ \\
\hline Batch 3 & & & \\
Sample & $\mathrm{B} 3-1$ & $\mathrm{~B} 3-2$ & $\mathrm{~B} 3-3$ \\
\hline Yield & $0.3716 \mathrm{~g}$ & $0.2536 \mathrm{~g}$ & $0.2100 \mathrm{~g}$ \\
Percent theoretical yield & $75.3 \%$ & $51.4 \%$ & $42.6 \%$ \\
Temperature & $210{ }^{\circ} \mathrm{C}$ & $210{ }^{\circ} \mathrm{C}$ & $210{ }^{\circ} \mathrm{C}$ \\
Synthesis time & $164.5 \mathrm{~h}$ & $95 \mathrm{~h}$ & $65.5 \mathrm{~h}$ \\
\hline
\end{tabular}

\section{ESI-B Rietveld refinement of PXRD data for remaining samples}

The Rietveld refinement of PXRD data was performed using the Fullprof suite. ${ }^{1}$ Data is shown in figure ESI-1 and parameters in tables ESI-2 to ESI-9. The background was described using a 7th degree Chebyshev polynomial. The peak shape was modelled using the Thompson-Cox-Hasting pseudo-Voigt function. In all cases the peak shape could be described by only refining the U and Y parameter. The experimental contributions to the peak shape was obtained from an Aluminium standard; also modelled using the Thompson-CoxHasting pseudo-Voigt function. In addition to the structural parameters, background and peak shape, a zero error was also refined for each sample. Sample B2-2 contained a small amount of impurity which was visible as a small peak at $1.63 \AA$.

Table ESI-2: Refined parameters for the Rietveld refinement of PXRD from sample B1-1

\begin{tabular}{cccccc}
\hline B1-1 & \multicolumn{5}{c}{} \\
\hline $\mathrm{a}$ & $\mathrm{b}$ & $\mathrm{c}$ & zero error & $\mathrm{R}_{\text {Bragg }}$ & \\
$7.2215 \AA$ & $7.2215 \AA$ & $17.2124 \AA$ & 0.0215 & $11.3 \%$ & \\
\hline $\mathrm{U}$ & $\mathrm{V}$ & $\mathrm{W}$ & $\mathrm{IG}$ & $\mathrm{X}$ & $\mathrm{Y}$ \\
0.0329 & 0 & 0 & 0 & 0 & 0.0259 \\
\hline Atom & $\mathrm{x}$ & $\mathrm{y}$ & $\mathrm{z}$ & $\begin{array}{c}\text { Debye-Waller } \\
\text { factor }\end{array}$ & occ \\
& & & & $1 \AA^{2}$ & 1 \\
$\mathrm{~K}$ & 0 & 0 & 0 & $1 \AA^{2}$ & 1 \\
$\mathrm{~S}$ & 0 & 0 & 0.31 & $0.7612 \AA^{2}$ & 1 \\
$\mathrm{Cr}$ & 0.5 & 0 & 0.5 & $1 \AA^{2}$ & 1 \\
$\mathrm{O} 1$ & 0 & 0 & 0.396 & $1 \AA^{2}$ & 1 \\
$\mathrm{O} 2$ & 0.2249 & 0.7751 & -0.0599 & $1 \AA^{2}$ & 1 \\
$\mathrm{O} 3$ & 0.13556 & 0.8644 & 0.1313 & $2 \AA^{2}$ & 1 \\
$\mathrm{D}$ & 0.185 & 0.815 & 0.111 & &
\end{tabular}

Table ESI-3: Refined parameters for the Rietveld refinement of PXRD from sample B1-2

\begin{tabular}{cccccc}
\hline $\mathrm{B} 1-2$ & \multicolumn{5}{c}{} \\
\hline $\mathrm{a}$ & $\mathrm{b}$ & $\mathrm{c}$ & zero error & $\mathrm{R}_{\text {Bragg }}$ & \\
$7.2187 \AA$ & $7.2187 \AA$ & $17.2341 \AA$ & -0.0356 & $11.2 \%$ & \\
\hline $\mathrm{U}$ & $\mathrm{V}$ & $\mathrm{W}$ & $\mathrm{IG}$ & $\mathrm{X}$ & $\mathrm{Y}$ \\
0.0106 & 0 & 0 & 0 & 0 & 0.0096 \\
\hline Atom & $\mathrm{x}$ & $\mathrm{y}$ & $\mathrm{z}$ & $\begin{array}{c}\text { Debye-Waller } \\
\text { factor }\end{array}$ & $\mathrm{occ}$ \\
& & & & & \\
$\mathrm{K}$ & 0 & 0 & 0 & $1 \AA^{2}$ & 1 \\
$\mathrm{~S}$ & 0 & 0 & 0.30511 & $1 \AA^{2}$ & 1 \\
$\mathrm{Cr}$ & 0.5 & 0 & 0.5 & $0.1052 \AA^{2}$ & 1 \\
$\mathrm{O} 1$ & 0 & 0 & 0.3866 & $1 \AA^{2}$ & 1 \\
$\mathrm{O} 2$ & 0.2202 & 0.7798 & -0.0564 & $1 \AA^{2}$ & 1 \\
$\mathrm{O} 3$ & 0.1333 & 0.8668 & 0.1338 & $1 \AA^{2}$ & 1 \\
$\mathrm{D}$ & 0.185 & 0.815 & 0.111 & $2 \AA^{2}$ & 1 \\
\hline
\end{tabular}


Table ESI-4: Refined parameters for the Rietveld refinement of PXRD from sample B2-1

\begin{tabular}{|c|c|c|c|c|c|}
\hline B2-1 & & & & & \\
\hline $\mathrm{a}$ & $\mathrm{b}$ & $\mathrm{c}$ & zero error & $\mathrm{R}_{\text {Bragg }}$ & \\
\hline $7.2191 \AA ̊$ & $7.2191 \AA$ & $17.1886 \AA$ & 0.0862 & $6.99 \%$ & \\
\hline $\mathrm{U}$ & $\mathrm{V}$ & $\mathrm{W}$ & IG & $\mathrm{X}$ & $\mathrm{Y}$ \\
\hline 0.0185 & 0 & 0 & 0 & 0 & 0.0050 \\
\hline Atom & $\mathrm{x}$ & $\mathrm{y}$ & $\begin{array}{l}\mathrm{Z} \\
\mathrm{z}\end{array}$ & $\begin{array}{l}\text { Debye-Waller } \\
\text { factor }\end{array}$ & occ \\
\hline K & 0 & 0 & 0 & $2.0589 \AA^{2}$ & 1 \\
\hline$S$ & 0 & 0 & 0.30721 & $1.3184 \AA^{2}$ & 1 \\
\hline $\mathrm{Cr}$ & 0.5 & 0 & 0.5 & $3.1026 \AA^{2}$ & 1 \\
\hline O1 & 0 & 0 & 0.3881 & $2.2626 \AA^{2}$ & 1 \\
\hline $\mathrm{O} 2$ & 0.2229 & 0.7771 & -0.0573 & $2.2626 \AA^{2}$ & 1 \\
\hline $\mathrm{O} 3$ & 0.1276 & 0.8723 & 0.1341 & $2.2626 \AA^{2}$ & 1 \\
\hline D & 0.185 & 0.815 & 0.111 & $2 \AA^{2}$ & 1 \\
\hline
\end{tabular}

Table ESI-6: Refined parameters for the Rietveld refinement of PXRD from sample B2-3

\begin{tabular}{cccccc}
\hline $\mathrm{B} 2-3$ & \multicolumn{5}{c}{} \\
\hline $\mathrm{a}$ & $\mathrm{b}$ & $\mathrm{c}$ & zero error & $\mathrm{R}_{\text {Bragg }}$ & \\
$7.2213 \AA$ & $7.2213 \AA$ & $17.1866 \AA$ & -0.0110 & $5.36 \%$ & \\
\hline $\mathrm{U}$ & $\mathrm{V}$ & $\mathrm{W}$ & $\mathrm{IG}$ & $\mathrm{X}$ & $\mathrm{Y}$ \\
0.0185 & 0 & 0 & 0 & 0 & 0.0056 \\
\hline Atom & $\mathrm{x}$ & $\mathrm{y}$ & $\mathrm{z}$ & $\begin{array}{c}\text { Debye-Waller } \\
\text { factor }\end{array}$ & $\mathrm{occ}$ \\
& & & $\mathrm{z}$ & $2.1785 \AA^{2}$ & 1 \\
$\mathrm{~K}$ & 0 & 0 & 0 & $0.2224 \AA^{2}$ & 1 \\
$\mathrm{~S}$ & 0 & 0 & 0.3060 & $0.25 \AA^{2}$ & 1 \\
$\mathrm{Cr}$ & 0.5 & 0 & 0.5 & $1.6000 \AA^{2}$ & 1 \\
$\mathrm{O} 1$ & 0 & 0 & 0.3911 & $0.6467 \AA^{2}$ & 1 \\
$\mathrm{O} 2$ & 0.2254 & 0.7746 & -0.0554 & $0.6467 \AA^{2}$ & 1 \\
$\mathrm{O} 3$ & 0.1283 & 0.8717 & 0.1355 & $0.6467 \AA^{2}$ & 1 \\
$\mathrm{D}$ & 0.185 & 0.815 & 0.111 & $2 \AA^{2}$ & 1 \\
\hline
\end{tabular}

Table ESI-8: Refined parameters for the Rietveld refinement of PXRD from sample B3-2

\begin{tabular}{|c|c|c|c|c|c|}
\hline B3-2 & & & & & \\
\hline $\mathrm{a}$ & b & c & zero error & $\mathrm{R}_{\text {Bragg }}$ & \\
\hline $7.2214 \AA$ & $7.2214 \AA$ & $17.1822 \AA$ & 0.0768 & $5.54 \%$ & \\
\hline $\mathrm{U}$ & $\mathrm{V}$ & W & IG & $\mathrm{X}$ & $\mathrm{Y}$ \\
\hline 0.0171 & 0 & 0 & 0 & 0 & 0.0086 \\
\hline Atom & $\mathrm{x}$ & $\mathrm{y}$ & $\begin{array}{l}\mathrm{Z} \\
\mathrm{Z}\end{array}$ & $\begin{array}{l}\text { Debye-Waller } \\
\text { factor }\end{array}$ & occ \\
\hline K & 0 & 0 & 0 & $3.8777 \AA^{2}$ & 1 \\
\hline S & 0 & 0 & 0.3092 & $1.2945 \AA^{2}$ & 1 \\
\hline $\mathrm{Cr}$ & 0.5 & 0 & 0.5 & $3.2895 \AA^{2}$ & 1 \\
\hline $\mathrm{O} 1$ & 0 & 0 & 0.3901 & $1.9168 \AA^{2}$ & 1 \\
\hline $\mathrm{O} 2$ & 0.2266 & 0.7734 & -0.0557 & $1.9168 \AA^{2}$ & 1 \\
\hline $\mathrm{O} 3$ & 0.1293 & 0.8707 & 0.1341 & $1.9168 \AA^{2}$ & 1 \\
\hline D & 0.185 & 0.815 & 0.111 & $2 \AA^{2}$ & 1 \\
\hline
\end{tabular}

Table ESI-5: Refined parameters for the Rietveld refinement of PXRD from sample B2-2

\begin{tabular}{cccccc}
\hline $\mathrm{B} 2-2$ & \multicolumn{5}{c}{} \\
\hline $\mathrm{a}$ & $\mathrm{b}$ & $\mathrm{c}$ & zero error & $\mathrm{R}_{\text {Bragg }}$ & \\
$7.2199 \AA$ & $7.2199 \AA$ & $17.2205 \AA$ & 0.0424 & $7.11 \%$ & \\
\hline $\mathrm{U}$ & $\mathrm{V}$ & $\mathrm{W}$ & $\mathrm{IG}$ & $\mathrm{X}$ & $\mathrm{Y}$ \\
0.0196 & 0 & 0 & 0 & 0 & 0.0124 \\
\hline Atom & $\mathrm{x}$ & $\mathrm{y}$ & $\mathrm{z}$ & $\begin{array}{c}\text { Debye-Waller } \\
\text { factor }\end{array}$ & $\mathrm{Occ}$ \\
& & & $\mathrm{z}$ & & \\
$\mathrm{K}$ & 0 & 0 & 0 & $0.8049 \AA^{2}$ & 1 \\
$\mathrm{~S}$ & 0 & 0 & 0.3096 & $1.6906 \AA^{2}$ & 1 \\
$\mathrm{Cr}$ & 0.5 & 0 & 0.5 & $2.8001 \AA^{2}$ & 1 \\
$\mathrm{O} 1$ & 0 & 0 & 0.3936 & $1.6419 \AA^{2}$ & 1 \\
$\mathrm{O} 2$ & 0.2220 & 0.7781 & -0.0555 & $1.6419 \AA^{2}$ & 1 \\
$\mathrm{O} 3$ & 0.1275 & 0.8725 & 0.1336 & $1.6419 \AA^{2}$ & 1 \\
$\mathrm{D}$ & 0.185 & 0.815 & 0.111 & $2 \AA^{2}$ & 1 \\
\hline
\end{tabular}

Table ESI-7: Refined parameters for the Rietveld refinement of PXRD from sample B3-1

\begin{tabular}{cccccc}
\hline B3-1 & \multicolumn{5}{l}{} \\
\hline $\mathrm{a}$ & $\mathrm{b}$ & $\mathrm{c}$ & zero error & $\mathrm{R}_{\text {Bragg }}$ & \\
$7.2215 \AA$ & $7.2215 \AA$ & $17.2343 \AA$ & 0.0166 & $7.80 \%$ & \\
\hline $\mathrm{U}$ & $\mathrm{V}$ & $\mathrm{W}$ & $\mathrm{IG}$ & $\mathrm{X}$ & $\mathrm{Y}$ \\
0.0203 & 0 & 0 & 0 & 0 & 0.0114 \\
\hline Atom & $\mathrm{X}$ & $\mathrm{y}$ & $\mathrm{z}$ & $\begin{array}{c}\text { Debye-Waller } \\
\text { factor }\end{array}$ & $\mathrm{Occ}$ \\
$\mathrm{K}$ & 0 & 0 & 0 & $0.3105 \AA^{2}$ & 1 \\
$\mathrm{~K}$ & 0 & 0 & 0.3092 & $1.7000 \AA^{2}$ & 1 \\
$\mathrm{Cr}$ & 0.5 & 0 & 0.5 & $2.8618 \AA^{2}$ & 1 \\
$\mathrm{O} 1$ & 0 & 0 & 0.3877 & $1.0768 \AA^{2}$ & 1 \\
$\mathrm{O} 2$ & 0.2232 & 0.7768 & -0.0583 & $1.0768 \AA^{2}$ & 1 \\
$\mathrm{O} 3$ & 0.1299 & 0.8700 & 0.1328 & $1.0768 \AA^{2}$ & 1 \\
$\mathrm{D}$ & 0.185 & 0.815 & 0.111 & $2 \AA^{2}$ & 1 \\
\hline
\end{tabular}

Table ESI-9: Refined parameters for the Rietveld refinement of PXRD from sample B3-3

\begin{tabular}{cccccc}
\hline $\mathrm{B} 3-3$ & \multicolumn{5}{l}{} \\
\hline $\mathrm{a}$ & $\mathrm{b}$ & $\mathrm{c}$ & zero error & $\mathrm{R}_{\mathrm{Bragg}}$ & \\
$7.2222 \AA$ & $7.2222 \AA$ & $17.2119 \AA$ & 0.0665 & $5.88 \%$ & \\
\hline $\mathrm{U}$ & $\mathrm{V}$ & $\mathrm{W}$ & $\mathrm{IG}$ & $\mathrm{X}$ & $\mathrm{Y}$ \\
0.0364 & 0 & 0 & 0 & 0 & 0.0102 \\
\hline Atom & $\mathrm{x}$ & $\mathrm{y}$ & $\mathrm{z}$ & $\begin{array}{c}\text { Debye-Waller } \\
\text { factor }\end{array}$ & $\mathrm{Occ}$ \\
& & & $\mathrm{z}$ & & \\
$\mathrm{K}$ & 0 & 0 & 0 & $3.4670 \AA^{2}$ & 1 \\
$\mathrm{~S}$ & 0 & 0 & 0.3077 & $2.8906 \AA^{2}$ & 1 \\
$\mathrm{Cr}$ & 0.5 & 0 & 0.5 & $4.8290 \AA^{2}$ & 1 \\
$\mathrm{O} 1$ & 0 & 0 & 0.3861 & $3.1119 \AA^{2}$ & 1 \\
$\mathrm{O} 2$ & 0.2251 & 0.7749 & -0.0574 & $3.1119 \AA^{2}$ & 1 \\
$\mathrm{O} 3$ & 0.1272 & 0.8727 & 0.1331 & $3.1119 \AA^{2}$ & 1 \\
$\mathrm{D}$ & 0.185 & 0.815 & 0.111 & $2 \AA^{2}$ & 1 \\
\hline
\end{tabular}




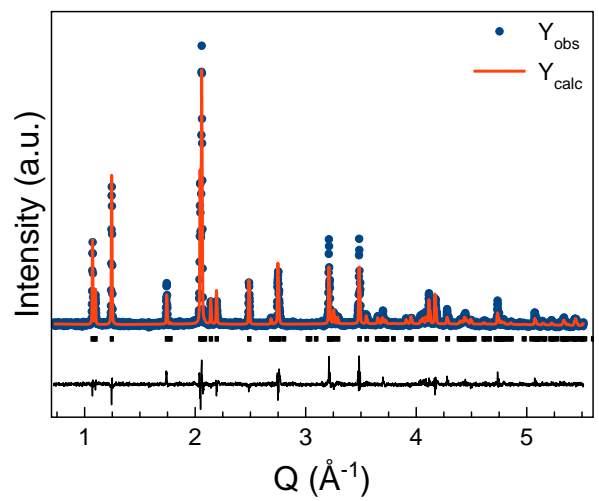

(a) Rietveld refinement of sample B1-1.

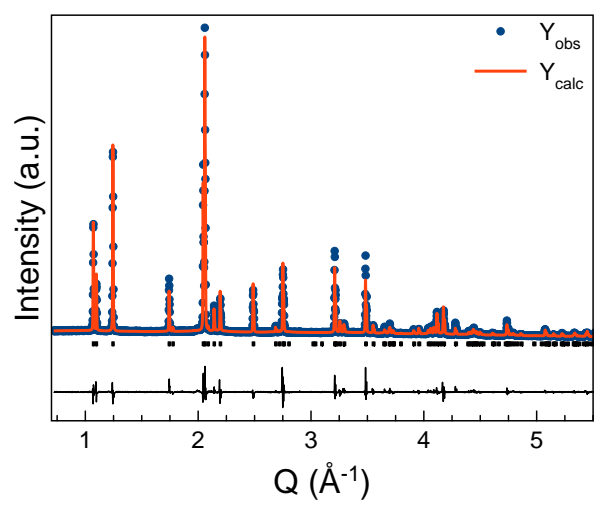

(c) Rietveld refinement of sample B2-1.

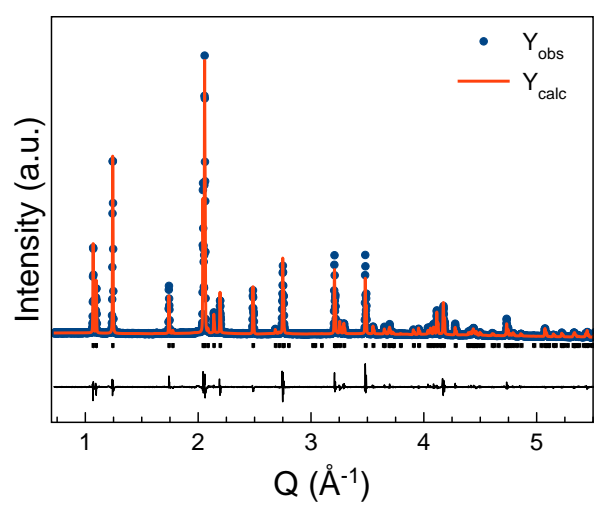

(e) Rietveld refinement of sample B2-3.

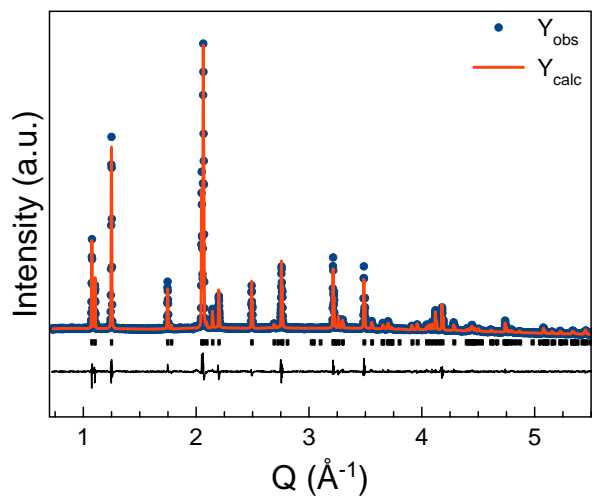

(g) Rietveld refinement of sample B3-2.

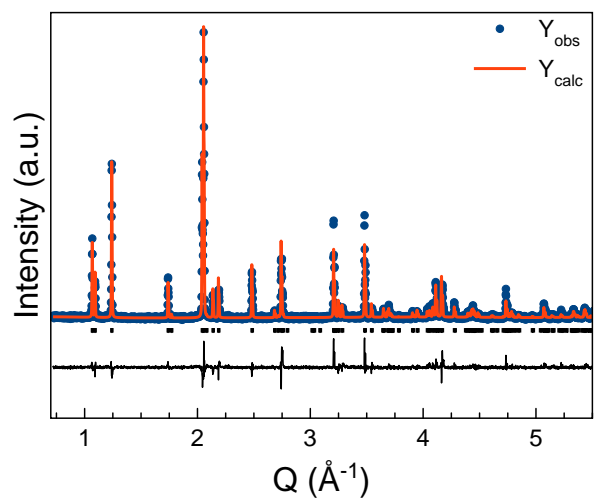

(b) Rietveld refinement of sample B1-2.

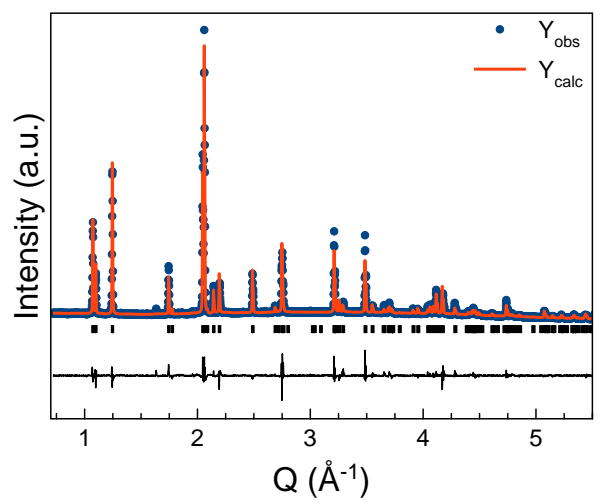

(d) Rietveld refinement of sample B2-2.

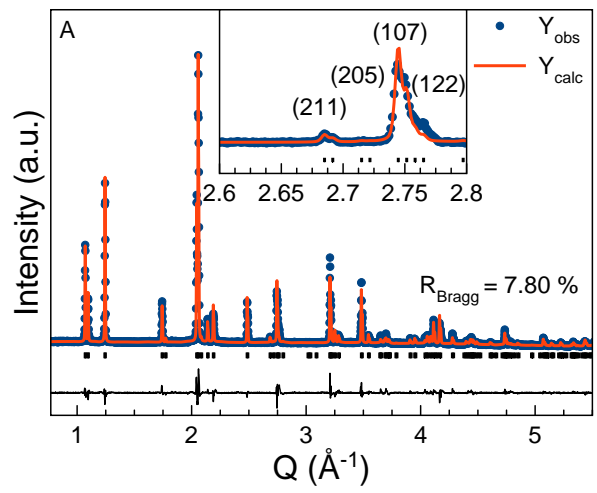

(f) Rietveld refinement of sample B3-1.

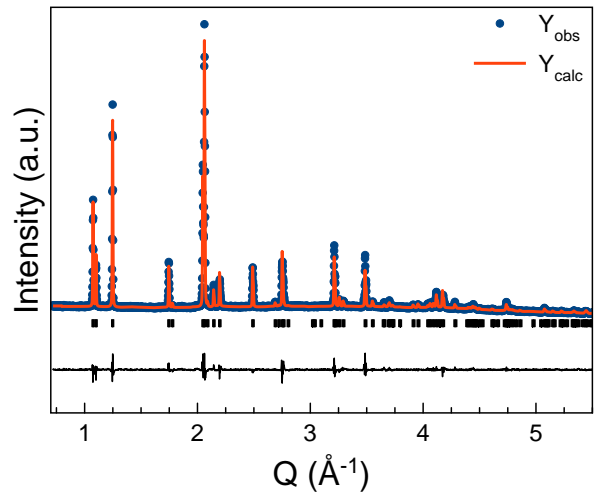

(h) Rietveld refinement of sample B3-3.

Figure ESI-1: Rietveld refinements of all Cr-jarosite samples. 


\section{ESI-C Rietveld refinement of powder neutron diffraction}

The temperature-dependent neutron powder diffraction experiment was carried out on a powder sample with mass 234.7 mg using two wavelengths, $\lambda=1.36 \AA$ And $\lambda=1.87 \AA$. The Rietveld refinement was performed using Topas academic to refine both datasets simultaneously. Each dataset had the background described using a 7th degree Chebyshev polynomial. The peak shape was modelled using the Thompson-Cox-Hasting pseudo-Voigt function. The structural parameters were constrained to be the same for each dataset. In addition to the structural parameters, background and peak shape, a zero error was also refined for each dataset. The $\mathrm{D}_{3} \mathrm{O}^{+}$replacing the $\mathrm{K}^{+}$is modelled only as an $\mathrm{O}$ at the K-site because at room temperature the deuterium atoms are rotating around the $(0$, 0 , 0$)$ position. ${ }^{2 / 3}$ The lack of fixed positions in the unit cell makes all the scattering from the deuterium atoms diffuse and non-contributing with regards to the Bragg intensity. The $\mathrm{Al}$ sample holder was refined using a Le bail refinement using a cubic $\mathrm{Al}$ phase with a $=4.0632$ $\AA$.

Table ESI-10: Refined parameters for the Rietveld refinement of PND from sample B3-1 with $\lambda=1.36 \AA$

\begin{tabular}{|c|c|c|c|c|c|}
\hline$\lambda=1.36 \AA$ & & & & & \\
\hline $\mathrm{a}$ & b & $\mathrm{c}$ & zero error & $\mathrm{R}_{\text {Bragg }}$ & \\
\hline $7.2427 \AA$ & $7.2427 \AA$ & $17.2835 \AA$ & 0.3756 & $2.39 \%$ & \\
\hline $\mathrm{U}$ & $\mathrm{V}$ & $\mathrm{W}$ & & & \\
\hline-0.3528 & 0.1285 & -0.4545 & & & \\
\hline $\mathrm{Z}$ & Y & $\mathrm{X}$ & & & \\
\hline 0.2843 & 0 & 0.0981 & & & \\
\hline Atom & $\mathrm{x}$ & $\mathrm{y}$ & $\mathrm{Z}$ & $\begin{array}{c}\text { Debye-Waller } \\
\text { factor }\end{array}$ & OCC \\
\hline $\mathrm{K}$ & 0 & 0 & 0 & $1.6980 \AA^{2}$ & 0.89 \\
\hline $\mathrm{O} 4$ & 0 & 0 & 0 & $1.6980 \AA^{2}$ & 0.21 \\
\hline S & 0 & 0 & 0.3055 & $0.6003 \AA^{2}$ & 1 \\
\hline $\mathrm{Cr}$ & 0.5 & 0 & 0.5 & $1.4949 \AA^{2}$ & 1 \\
\hline $\mathrm{O} 1$ & 0 & 0 & 0.3902 & $1.2426 \AA^{2}$ & 1 \\
\hline $\mathrm{O} 2$ & 0.224 & 0.776 & -0.0574 & $1.2426 \AA^{2}$ & 1 \\
\hline $\mathrm{O} 3$ & 0.1272 & 0.8727 & 0.1370 & See table ESI-12 & 1 \\
\hline D & 0.1952 & 0.8048 & 0.1107 & See table $\overline{\text { ESI-12 }}$ & \\
\hline
\end{tabular}

Table ESI-11: Refined parameters for the Rietveld refinement of PND from sample B3-1 with $\lambda=1.87 \AA$

\begin{tabular}{|c|c|c|c|c|c|}
\hline$\lambda=1.87$ & & & & & \\
\hline $\mathrm{a}$ & $\mathrm{b}$ & $\mathrm{c}$ & zero error & $\mathrm{R}_{\text {Bragg }}$ & \\
\hline $7.2427 \AA$ & $7.2427 \AA$ & $17.2835 \AA$ & 0.4042 & $2.43 \%$ & \\
\hline $\mathrm{U}$ & V & $\mathrm{W}$ & & & \\
\hline-0.63055 & 0.1198 & -0.8157 & & & \\
\hline Z & Y & $\mathrm{X}$ & & & \\
\hline 0.5318 & 0 & 0.00075 & & & \\
\hline Atom & $\mathrm{x}$ & $\mathrm{y}$ & $\mathrm{Z}$ & $\begin{array}{c}\text { Debye-Waller } \\
\text { factor }\end{array}$ & occ \\
\hline K & 0 & 0 & 0 & $1.6980 \AA^{2}$ & 0.89 \\
\hline O4 & 0 & 0 & 0 & $1.6980 \AA^{2}$ & 0.21 \\
\hline S & 0 & 0 & 0.3055 & $0.6003 \AA^{2}$ & 1 \\
\hline $\mathrm{Cr}$ & 0.5 & 0 & 0.5 & $1.4949 \AA^{2}$ & 1 \\
\hline O1 & 0 & 0 & 0.3902 & $1.2426 \AA^{2}$ & 1 \\
\hline $\mathrm{O} 2$ & 0.224 & 0.776 & -0.0574 & $1.2426 \AA^{2}$ & 1 \\
\hline $\mathrm{O} 3$ & 0.1272 & 0.8727 & 0.1370 & See table ESI-12 & 1 \\
\hline $\mathrm{D}$ & 0.1952 & 0.8048 & 0.1107 & See table $\overline{\text { ESI-12 }}$ & \\
\hline
\end{tabular}


Table ESI-12: Anisotropic Debye-Waller factor for the Rietveld refinement of PND from sample B3-1 with $\lambda=1.36 \AA ̊$ and $\lambda=1.87 \AA$

\begin{tabular}{ccc}
\hline $\begin{array}{c}\text { Anisotropic } \\
\text { DW factor }\end{array}$ & $\mathrm{O} 3$ & $\mathrm{D}$ \\
$\mathrm{B}_{11}$ & $0.6238 \AA^{2}$ & $1.6439 \AA^{2}$ \\
$\mathrm{~B}_{22}$ & $0.6238 \AA^{2}$ & $1.6439 \AA^{2}$ \\
$\mathrm{~B}_{33}$ & $1.3691 \AA^{2}$ & $2.8471 \AA^{2}$ \\
$\mathrm{~B}_{12}$ & $0.4595 \AA^{2}$ & $0.5527 \AA^{2}$ \\
$\mathrm{~B}_{13}$ & $0.0355 \AA^{2}$ & $0.0608 \AA^{2}$ \\
$\mathrm{~B}_{23}$ & $-0.0355 \AA^{2}$ & $-0.0608 \AA^{2}$ \\
\hline
\end{tabular}

\section{ESI-D Additional ${ }^{2} \mathrm{H}$ MAS NMR data}

Variable temperature ${ }^{2} \mathrm{H}$ MAS NMR spectra were recorded in the temperature setting from -40 to $100{ }^{\circ} \mathrm{C}$ using a 3.2 mm $\mathrm{HXY}$ MAS NMR probe using 16 and $17 \mathrm{kHz}$ spinning speeds. The exact sample temperature was determined using the $\delta_{\text {iso }}\left({ }^{207} \mathrm{~Pb}\right)$ of lead(II) nitrate as a NMR thermometer. ${ }^{4}$ The temperature dependence of the $\mathrm{Cr}_{2}-\mathrm{OD}(\mathrm{K})$ site was found to $-2.34 \mathrm{ppm} / \mathrm{K}$ by linear fit of $\delta\left({ }^{2} \mathrm{H}\right)$ as a function of temperature (Fig. ESI-4).

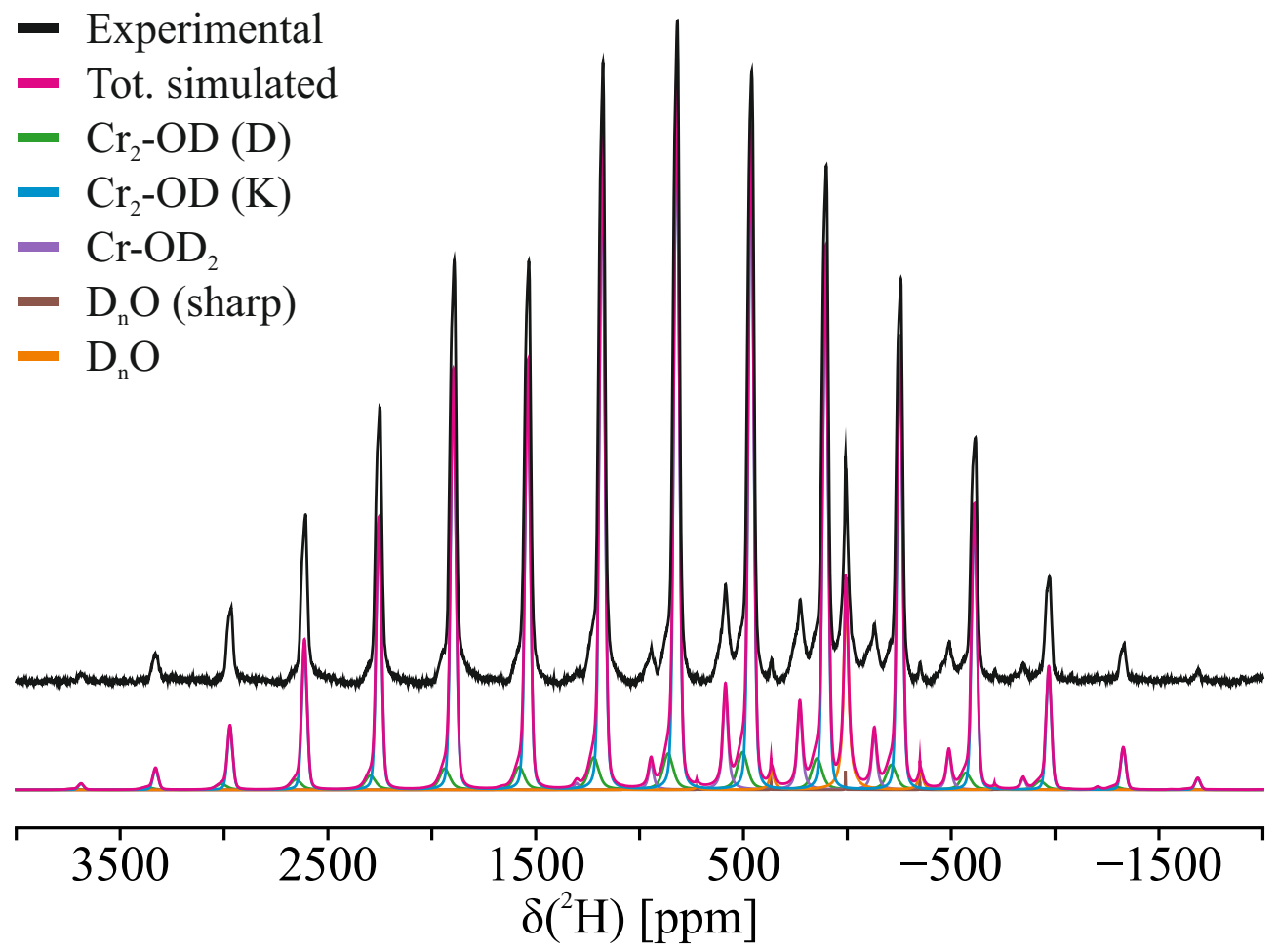

Figure ESI-2: Experimental and simulated ${ }^{2} \mathrm{H}$ MAS NMR spectrum of sample B3-1 recorded with $33 \mathrm{KHz}$ spinning speed using the parameters in Table ESI-13. 
Table ESI-13: ${ }^{2} \mathrm{H}$ NMR parameters obtained from fitting of the experimental spectra for the individual spectra. The total shift anisotropy is given in the Haeberlen convention c.f., main text, where $\beta$ is an angle between the principal axes of the CSA and quadrupole tensor. The other two Euler angles, $\alpha(\gamma)$ are undefined for $\eta_{\sigma}\left(\eta_{Q}\right)=0$ and could not be unambiguously determined. The error on the average values is estimated from the standard deviation. The relative concentration of the different sites for all samples is illustrated in Fig. ESI-3 The line shape of the $\mathrm{Cr}_{2}-\mathrm{OD}(\mathrm{K})$ resonance is clearly asymmetric, reflecting a distribution of $\delta_{\text {iso }}\left({ }^{2} \mathrm{H}\right)$ due to different local environments, but the other NMR parameters are similar. For B2-1 this is clearly seen as a resonance at $\delta_{\text {iso }}\left({ }^{2} \mathrm{H}\right)=804$ ppm, which constitute ca. $40 \%$ of the total intensity.

\begin{tabular}{|c|c|c|c|c|c|c|c|c|}
\hline Sample & Group & $\delta_{\text {iso }}\left({ }^{2} \mathrm{H}\right)[\mathrm{ppm}]$ & $\Delta[\mathrm{ppm}]$ & $\eta_{\sigma}$ & $\mathrm{C}_{Q}[\mathrm{MHz}]$ & $\eta_{Q}$ & $\beta$ [deg] & Intensity [\%] \\
\hline \multirow[t]{5}{*}{ B1-1 } & $\mathrm{Cr}_{2}-\mathrm{OD}(\mathrm{D})$ & $876(10)$ & $-900(100)$ & $1.00(10)$ & $0.240(40)$ & $0.10(10)$ & $39(5)$ & $9(1)$ \\
\hline & $\mathrm{Cr}_{2}-\mathrm{OD}(\mathrm{K})$ & $828(3)$ & $-960(50)$ & $1.00(10)$ & $0.222(10)$ & $0.10(10)$ & $52(5)$ & $76(1)$ \\
\hline & $\mathrm{Cr}-\mathrm{OD}_{2}$ & $230(3)$ & $600(50)$ & $0.00(10)$ & $0.109(5)$ & $0.63(10)$ & $64(5)$ & $7(1)$ \\
\hline & $\mathrm{D}_{n} \mathrm{O}$ (sharp) & $9(1)$ & $0(10)$ & $0.00(10)$ & $0.100(5)$ & $0.00(10)$ & $0(5)$ & $1>$ \\
\hline & $\mathrm{D}_{n} \mathrm{O}$ & $7(2)$ & $0(10)$ & $0.00(10)$ & $0.050(5)$ & $0.00(10)$ & $0(5)$ & $8(1)$ \\
\hline \multirow[t]{5}{*}{ B1-2 } & $\mathrm{Cr}_{2}-\mathrm{OD}(\mathrm{D})$ & $876(10)$ & $-1090(100)$ & $1.00(10)$ & $0.240(40)$ & $0.10(10)$ & $39(5)$ & 13(1) \\
\hline & $\mathrm{Cr}_{2}-\mathrm{OD}(\mathrm{K})$ & $828(3)$ & $-960(50)$ & $1.00(10)$ & $0.222(10)$ & $0.10(10)$ & $52(5)$ & 77(1) \\
\hline & $\mathrm{Cr}-\mathrm{OD}_{2}$ & $230(3)$ & $780(50)$ & $0.00(10)$ & $0.092(5)$ & $0.80(10)$ & $70(5)$ & $9(1)$ \\
\hline & $\mathrm{D}_{n} \mathrm{O}$ (sharp) & $9(1)$ & $0(10)$ & $0.00(10)$ & $0.100(5)$ & $0.00(10)$ & $0(5)$ & $1>$ \\
\hline & $\mathrm{D}_{n} \mathrm{O}$ & $7(2)$ & $0(10)$ & $0.00(10)$ & $0.050(5)$ & $0.00(10)$ & $0(5)$ & $1(1)$ \\
\hline \multirow[t]{5}{*}{ B2-1 } & $\mathrm{Cr}_{2}-\mathrm{OD}(\mathrm{D})$ & $864(10)$ & $-1120(100)$ & $1.00(10)$ & $0.240(40)$ & $0.10(10)$ & $48(5)$ & $15(1)$ \\
\hline & $\mathrm{Cr}_{2}-\mathrm{OD}(\mathrm{K})$ & $823(3)$ & $-930(50)$ & $1.00(10)$ & $0.223(10)$ & $0.11(10)$ & $53(5)$ & $73(2)$ \\
\hline & $\mathrm{Cr}-\mathrm{OD}_{2}$ & $226(3)$ & $670(50)$ & $0.00(10)$ & $0.107(5)$ & $1.00(10)$ & $59(5)$ & $8(1)$ \\
\hline & $\mathrm{D}_{n} \mathrm{O}$ (sharp) & $8(1)$ & $0(10)$ & $0.00(10)$ & $0.100(5)$ & $0.00(10)$ & $0(5)$ & $1>$ \\
\hline & $\mathrm{D}_{n} \mathrm{O}$ & $6(2)$ & $0(10)$ & $0.00(10)$ & $0.050(5)$ & $0.00(10)$ & $0(5)$ & $4(1)$ \\
\hline \multirow[t]{6}{*}{ B2-2 } & $\mathrm{Cr}_{2}-\mathrm{OD}(\mathrm{D})$ & $860(10)$ & $-1070(100)$ & $1.00(10)$ & $0.240(40)$ & $0.10(10)$ & $47(5)$ & $18(1)$ \\
\hline & $\mathrm{Cr}_{2}-\mathrm{OD}(\mathrm{K})$ & $822(5)$ & $-940(50)$ & $1.00(10)$ & $0.219(15)$ & $0.10(10)$ & $54(5)$ & $64(2)$ \\
\hline & $\mathrm{Cr}_{2}-\mathrm{OD}(? ?)$ & $804(5)$ & $-1000(50)$ & $1.00(10)$ & $0.226(15)$ & $0.10(10)$ & $49(5)$ & - \\
\hline & $\mathrm{Cr}-\mathrm{OD}_{2}$ & $226(3)$ & $510(50)$ & $0.00(10)$ & $0.110(5)$ & $1.00(10)$ & $70(5)$ & 11(1) \\
\hline & $\mathrm{D}_{n} \mathrm{O}$ (sharp) & $9(1)$ & $0(10)$ & $0.00(10)$ & $0.100(5)$ & $0.00(10)$ & $0(5)$ & $1>$ \\
\hline & $\mathrm{D}_{n} \mathrm{O}$ & $6(2)$ & $0(10)$ & $0.00(10)$ & $0.050(5)$ & $0.00(10)$ & $0(5)$ & $7(1)$ \\
\hline \multirow[t]{5}{*}{ B2-3 } & $\mathrm{Cr}_{2}-\mathrm{OD}(\mathrm{D})$ & $865(10)$ & $-900(100)$ & $1.00(10)$ & $0.240(40)$ & $0.10(10)$ & $38(5)$ & 19(1) \\
\hline & $\mathrm{Cr}_{2}-\mathrm{OD}(\mathrm{K})$ & $823(3)$ & $-930(50)$ & $1.00(10)$ & $0.222(10)$ & $0.09(10)$ & $53(5)$ & $63(2)$ \\
\hline & $\mathrm{Cr}-\mathrm{OD}_{2}$ & $228(3)$ & $690(50)$ & $0.00(10)$ & $0.100(5)$ & $0.60(10)$ & $65(5)$ & 11(1) \\
\hline & $\mathrm{D}_{n} \mathrm{O}$ (sharp) & $9(1)$ & $0(10)$ & $0.00(10)$ & $0.100(5)$ & $0.00(10)$ & $0(5)$ & $1>$ \\
\hline & $\mathrm{D}_{n} \mathrm{O}$ & $5(2)$ & $0(10)$ & $0.00(10)$ & $0.050(5)$ & $0.00(10)$ & $0(5)$ & $7(1)$ \\
\hline \multirow[t]{5}{*}{ B3-1 } & $\mathrm{Cr}_{2}-\mathrm{OD}(\mathrm{D})$ & $862(10)$ & $-1100(100)$ & $1.00(10)$ & $0.240(40)$ & $0.10(10)$ & $46(5)$ & $10(1)$ \\
\hline & $\mathrm{Cr}_{2}-\mathrm{OD}(\mathrm{K})$ & $821(3)$ & $-1000(50)$ & $1.00(10)$ & $0.222(10)$ & $0.14(10)$ & $53(5)$ & $79(2)$ \\
\hline & $\mathrm{Cr}-\mathrm{OD}_{2}$ & $228(3)$ & $720(50)$ & $0.00(10)$ & $0.100(5)$ & $0.69(10)$ & $68(5)$ & $6(1)$ \\
\hline & $\mathrm{D}_{n} \mathrm{O}$ (sharp) & $9(1)$ & $0(10)$ & $0.00(10)$ & $0.100(5)$ & $0.00(10)$ & $0(5)$ & $1>$ \\
\hline & $\mathrm{D}_{n} \mathrm{O}$ & $5(2)$ & $0(10)$ & $0.00(10)$ & $0.050(5)$ & $0.00(10)$ & $0(5)$ & $5(2)$ \\
\hline \multirow[t]{5}{*}{ B3-2 } & $\mathrm{Cr}_{2}-\mathrm{OD}(\mathrm{D})$ & $870(10)$ & $-1110(100)$ & $1.00(10)$ & $0.230(40)$ & $0.10(10)$ & $40(5)$ & 19(1) \\
\hline & $\mathrm{Cr}_{2}-\mathrm{OD}(\mathrm{D})$ & $827(3)$ & $-850(50)$ & $1.00(10)$ & $0.224(10)$ & $0.07(10)$ & $55(5)$ & $63(1)$ \\
\hline & $\mathrm{Cr}-\mathrm{OD}_{2}$ & $230(3)$ & $700(50)$ & $0.00(10)$ & $0.105(5)$ & $1.00(10)$ & $55(5)$ & 11(1) \\
\hline & $\mathrm{D}_{n} \mathrm{O}$ (sharp) & $10(1)$ & $0(10)$ & $0.00(10)$ & $0.100(5)$ & $0.00(10)$ & $0(5)$ & $1>$ \\
\hline & $\mathrm{D}_{n} \mathrm{O}$ & $8(2)$ & $0(10)$ & $0.00(10)$ & $0.050(5)$ & $0.00(10)$ & $0(5)$ & $7(1)$ \\
\hline \multirow{6}{*}{$\begin{array}{l}\text { Average } \\
\text { values }\end{array}$} & $\mathrm{Cr}_{2}-\mathrm{OD}(\mathrm{D})$ & $868(7)$ & $-1040(100)$ & $1.00(10)$ & $0.240(3)$ & $0.10(10)$ & 42(4) & - \\
\hline & $\mathrm{Cr}_{2}-\mathrm{OD}(\mathrm{K})$ & $825(3)$ & $-940(50)$ & $1.00(10)$ & $0.222(2)$ & $0.10(4)$ & $53(1)$ & - \\
\hline & $\mathrm{Cr}_{2}-\mathrm{OD}(? ?)$ & $804(5)$ & $-1000(50)$ & $1.00(10)$ & $0.226(5)$ & $0.10(10)$ & $49(6)$ & - \\
\hline & $\mathrm{Cr}-\mathrm{OD}_{2}$ & $228(2)$ & $670(90)$ & $0.00(30)$ & $0.103(7)$ & $0.82(18)$ & $64(6)$ & - \\
\hline & $\mathrm{D}_{n} \mathrm{O}$ (sharp) & $9(1)$ & $0(10)$ & $0.00(10)$ & $0.100(5)$ & $0.00(10)$ & $0(5)$ & - \\
\hline & $\mathrm{D}_{n} \mathrm{O}$ & $6(2)$ & $0(10)$ & $0.00(10)$ & $0.050(5)$ & $0.00(10)$ & $0(5)$ & - \\
\hline
\end{tabular}




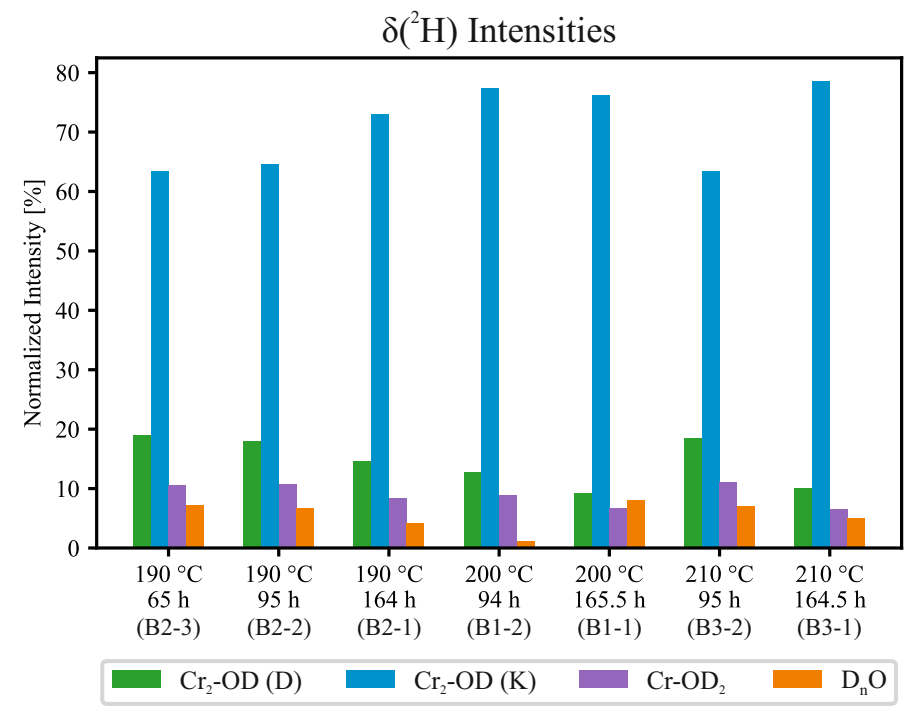

Figure ESI-3: The relative intensity of the different local ${ }^{2} \mathrm{H}$ environments in the samples using the data in Table ESI-13

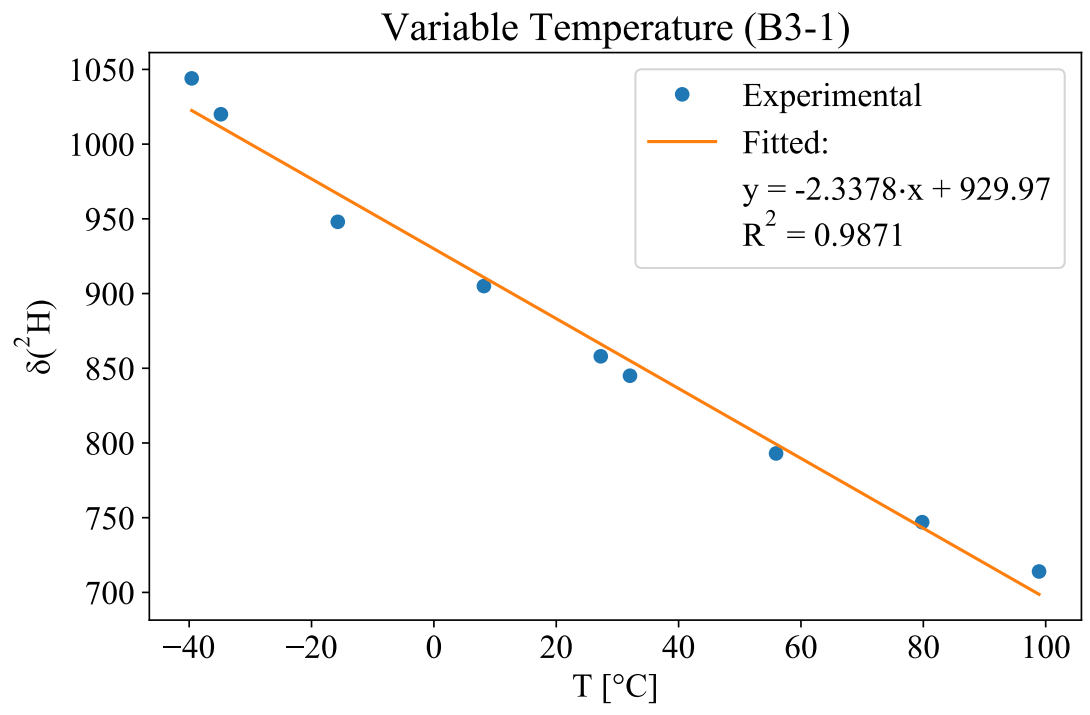

Figure ESI-4: $\delta_{\text {iso }}\left({ }^{2} \mathrm{H}\right)$ for the $\mathrm{Cr}_{2}$-OD (K) site as a function of temperature illustrating the linear temperature dependence of $\delta\left({ }^{2} \mathrm{H}\right)$.

\section{ESI-E Scanning Electron microscopy of selected samples}

SEM was performed on samples B3-1 and B2-1, see figure ESI-5 

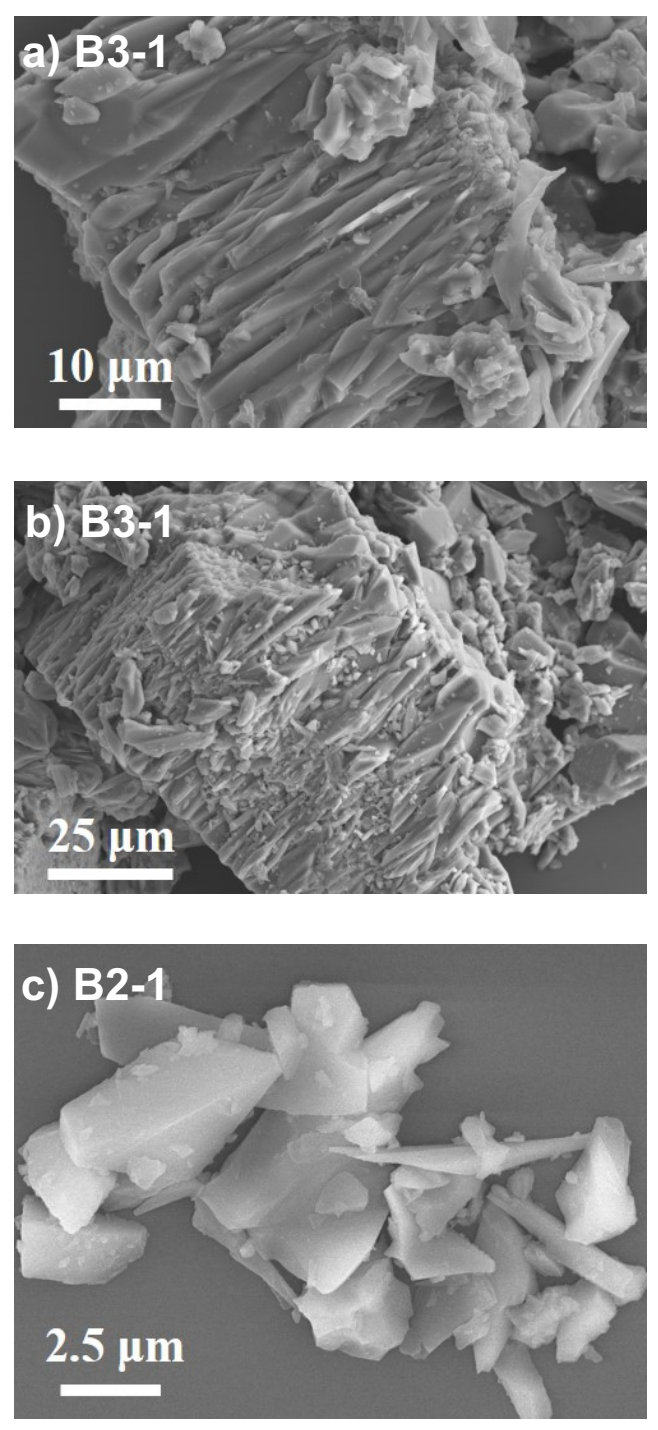

Figure ESI-5: (a) and (b) SEM images of Sample B3-1, which show that the large particles are agglomerates of several, smaller particles in agreement with the pronounced stacking disorder observed in PXRD and neutron diffraction as well as the distribution on $\delta_{\text {iso }}\left({ }^{2} \mathrm{H}\right)$. (c) SEM image of individual, smaller crystals from sample B2-1. Notice that different magnification was used in the three images, as indicated by the scale bar.

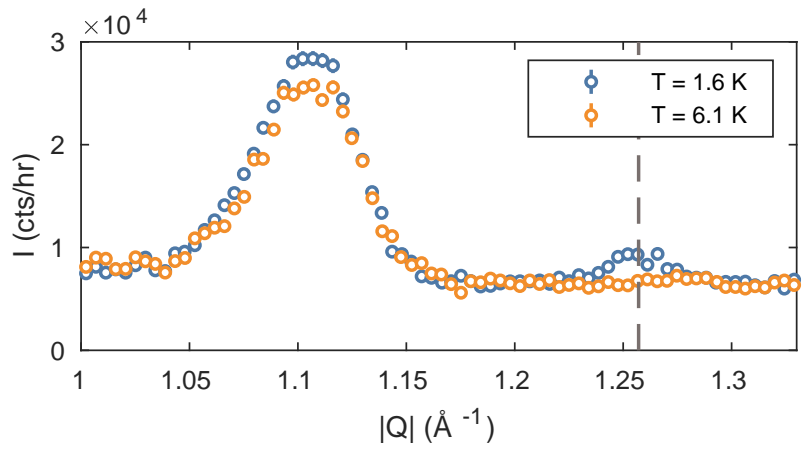

Figure ESI-6: $2 \theta$ scan across the elastic Bragg peaks at two temperatures above and below the phase transition, showing the growth of the (012) Bragg peak. Grey dashed line indicates the peak position. Errorbars are smaller than markers. 


\section{ESI-F Temperature-dependent neutron diffraction}

The temperature-dependent neutron powder diffraction experiment was carried out on a powder sample with mass 234.7 mg. First $|Q|$ was scanned across the peak position of the magnetic (012) peak at two temperatures above and below $T_{N}$ in order to determine the exact peak position. This is shown in figure ESI-6, where the (012) peak position, $|Q| \approx 1.257 \AA^{-1}$, is indicated by the grey dashed line. The strong peak at $|Q| \approx 1.1 \AA^{-1}$ is the sum of the structural (003) and (101) peaks, on top of which the magnetic (101) and (111) peaks develops. The temperature-dependent signal of (012) is then obtained by counting at the peak position for a given temperature after stabilization. Temperature stabilization was carefully checked, and only data points with temperature fluctuations less than $0.2 \mathrm{~K}$ are included in the fit in in the main article. 


\section{Notes and references}

[1] J. Rodríguez-Carvajal, Physica B, 1993, 192, 55 - 69.

[2] U. G. Nielsen, I. Heinmaa, A. Samoson, J. Majzlan and C. P. Grey, Chemistry of Materials, 2011, 23, 3176-3187.

[3] J. D. Gale, K. Wright and K. A. Hudson-Edwards, American Mineralogist, 2010, 95, 1109-1112.

[4] A. Bielecki and D. P. Burum, Journal of Magnetic Resonance, Series A, 1995, 116, 215-220. 